\title{
Ste20-like protein kinases are required for normal localization of cell growth and for cytokinesis in budding yeast
}

\author{
Fatima Cvrčková, ${ }^{1,4}$ Claudio De Virgilio, ${ }^{2}$ Edward Manser, ${ }^{3}$ John R. Pringle, $^{2}$ and Kim Nasmyth ${ }^{1,5}$ \\ ${ }^{1}$ Institute of Molecular Pathology (IMP), A-1030 Wien, Austria; ${ }^{2}$ University of North Carolina, Chapel Hill, North Carolina \\ 27599-3280 USA; ${ }^{3}$ Institute of Molecular and Cell Biology (IMCB), National University of Singapore, 0511 Singapore
}

\begin{abstract}
The yeast Ste20 protein kinase is involved in pheromone response. Mammalian homologs of Ste20 exist, but their function remains unknown. We identified a novel yeast STE20 homolog, CLA4, in a screen for mutations lethal in the absence of the $G_{1}$ cyclins $C \ln 1$ and $C \ln 2$. Cla4 is involved in budding and cytokinesis and interacts with Cdc42, a GTPase required for polarized cell growth. Despite a cytokinesis defect, cla4 mutants are viable. However, double cla4 ste20 mutants cannot maintain septin rings at the bud neck and cannot undergo cytokinesis. Mutations in $C D C 12$, which encodes one of the septins, were found in the same screen. Cla4 and Ste20 kinases apparently share a function in localizing cell growth with respect to the septin ring.
\end{abstract}

[Key Words: Cell cycle; cell morphogenesis; cytokinesis; GTPase; septins]

Received February 6, 1995; revised version accepted June 16, 1995.

Mechanisms of cytokinesis are extremely variable among eukaryotes. One variant of this theme is cell division by budding, typical for yeasts. The cleavage furrow in animal cells or the preprophase band (a cytoskeletal structure determining the future cell division plane) in plant cells forms only after most of the growth required to double the mass of the cell has occurred, whereas in budding, the formation of the "cleavage furrow" (bud neck) precedes the bulk of cell growth. Unlike cleavage or fission, budding is dependent on the ability to direct growth exclusively to one side of the division plane-to the bud. Despite differences in timing and morphology, at least some of the molecular mechanisms underlying budding and cytokinesis are conserved among eukaryotes (see e.g., Shinjo et al. 1990; Manser et al. 1994; Neufeld and Rubin 1994). Studies in yeast may be as useful for understanding cytokinesis and its regulation as they have been for elucidating the mechanisms of cell cycle control by cyclin-dependent protein kinases (for reviews, see Nasmyth 1993; Pines 1993).

Like other cell cycle processes, the timing of cytokinesis must be carefully regulated. In yeast, the first step toward cytokinesis is budding. The processes leading to bud emergence begin in late $G_{1}$, concurrently with the onset of DNA replication and with the duplication of the spindle pole body. The simultaneous onset of these three processes (often referred to as "Start") occurs as a conse-

\footnotetext{
${ }^{4}$ Present address: Department of Plant Physiology, Faculty of Science, Charles University, Viničná 5, CZ-12843 Praha 2, Czech Republic.

${ }^{5}$ Corresponding author.
}

quence of the activation of a cyclin-dependent protein kinase, Cdc28, by at least one of the $\mathrm{G}_{1}$ cyclins $C \ln 1$, $\mathrm{Cln} 2$, and $\mathrm{Cln} 3$. Under normal conditions, $\mathrm{Cln} 3$ induces the accumulation of $C \ln 1$ and $C \ln 2$, which then trigger budding and DNA replication (Richardson et al. 1989; Dirick and Nasmyth 1991; Tyers et al. 1993; L. Dirick, pers. comm.).

Bud emergence results from several distinct events (for review, see Chant 1994). The cell must choose a site on its surface (the bud site) and direct growth toward this site, ensuring at the same time that no other part of the cell exterior grows.

The first event necessary for budding-bud site establishment-requires the products of multiple genes including $C D C 42$, which codes for a Rho-like GTPase that is localized at the bud site (Johnson and Pringle 1990; Ziman et al. 1993), CDC24, coding for a GDP/GTP exchange factor (Sloat et al. 1981; Zheng et al. 1994), and $C D C 43 / C A L 1$, encoding a prenyl transferase required to attach Cdc42 to membranes (Johnson et al. 1990; Ohya et al. 1995). The nonessential genes RSR1/BUD1, $B U D 2, B U D 3, B U D 4$, and $B U D 5$ are responsible for nonrandom localization of the bud site with respect to the previous bud (see Chant 1994). One of them, BUD2, is essential for budding in cells lacking $C \ln 1$ and $C \ln 2$, suggesting that bud emergence is controlled by $\mathrm{Cln} 1$ and Cln2 (Benton et al. 1993; Cvrčková and Nasmyth 1993).

A second prerequisite for budding is a change in cell growth mode that occurs at Start. Pre-Start cells grow in a nonpolar manner, increasing their size but maintaining their shape. After Start, growth becomes limited to a part of the cell-the nascent bud. Polarization of growth is 
accompanied by translocation of cortical actin to the growing area, triggered by $C \operatorname{Cd} 28$ and $C \ln 1$ or $C \ln 2$. Overexpression of Cln1 or Cln2 causes "hyperpolarized" growth, suggesting that $\mathrm{Cln} 1$ and $C \ln 2$ have a role in directing growth toward the bud site (or toward the bud tip in budded cells). Later in the cell cycle, Cln cyclins are replaced by the mitotic $B$ cyclins, at which point the bud begins to expand isometrically (Lew and Reed 1993).

The third prerequisite of normal bud development is the establishment of a "border" between the bud and the mother cell and restriction of surface growth to the bud. Unlike the previous steps, which are required not only for budding but also for the morphological changes ("shmooing") in haploid cells differentiating into gametes, border formation is specific for budding. The border is marked by a ring of $10-\mathrm{nm}$ filaments attached to the cytoplasmic membrane. The ring forms around the bud site at the time of bud emergence and persists at the bud neck till cytokinesis (Byers and Goetsch 1976). Mutants in $C D C 3, C D C 10, C D C 11$, and $C D C 12$ fail to assemble the ring, produce malformed buds, and cannot undergo cytokinesis. $C D C 3, C D C 10, C D C 11$ and CDC12 encode structural components of the ring (Haarer and Pringle 1987; Ford and Pringle 1991; Kim et al. 1991), which are proteins closely related to each other, to products of several anonymous mammalian cDNAs and to the Drosophila peanut (Pnut) protein required for cytokinesis (Neufeld and Rubin 1994). Members of this protein family were termed "septins" (Sanders and Field 1994).

Other proteins involved in budding are also evolutionarily conserved. Homologs of $\mathrm{Cdc} 42$ have been found in higher eukaryotes (Shinjo et al. 1990). Their biological function remains largely unknown; the expression of mutationally activated Cdc42 in fibroblasts may cause a cytokinesis defect (T. Leung, E.M. Lim, and L. Lim, unpubl.). Biochemical partners of Cdc42 in mammalian brain tissue were found (Manser et al. 1993, 1994). One of these partners, the Pak protein kinase, is related to a yeast protein-Ste20 - necessary for the response of haploid cells to sexual pheromones. Ste20 transduces the signal elicited by the binding of pheromone to a membrane receptor toward a protein kinase cascade consisting of Ste11, Ste7, and Fus3/Kss1, one of several yeast homologs of the mammalian MAPK system. Induction of the kinase cascade leads to transcriptional activation of pheromone-regulated genes and to cell cycle arrest in $G_{1}$ as a prelude to conjugation. Loss of Ste20 or other components of the pheromone response pathway does not affect budding or the establishment of cell polarity in haploids (Leberer et al. 1992; for review, see Ammerer 1994). The interaction between the mammalian Ste20 and $\mathrm{Cdc} 42$ homologs was therefore surprising. So far, there is only one observation suggesting a role for Ste20 in morphogenesis: Ste20 is, among other components of the pheromone response pathway, required for the formation of pseudomycelia in nitrogen-starved diploid cells (Liu et al. 1993). It is, however, unclear whether Ste20 functions in cell morphogenesis or in perceiving nutrient conditions during pseudomycelial differentiation.
How is budding linked to the rest of the cell cycle? We described previously the isolation of mutants defective in bud emergence only in the absence of $C \ln 1$ and $C \ln 2$ and proposed that $C \ln 1$ and $C \ln 2$ are involved in bud site establishment (Cvrčková and Nasmyth 1993). The same genetic screen yielded mutants unable to undergo cytokinesis because of a defect in bud neck morphogenesis, suggesting that $C \ln 1$ and $C \ln 2$ have a role also in determining the border between the mother cell and its bud. One of the genes required for cytokinesis in $\operatorname{cln} 1 \mathrm{cln} 2$ cells, CLA10, is allelic to CDC12, suggesting that septin ring assembly or function may be controlled by $\mathrm{Cln} 1$ and $\mathrm{Cln} 2$. Other mutants with a similar phenotype define a novel gene, CLA4, that codes for a putative protein kinase related to Ste20 and Pak. Similar to Pak, Cla4 binds Cdc42. CLA4 is a nonessential gene, but Cla4 and Ste20 share an essential function required for the restriction of cell growth to the portion of cell surface enclosed by the septin ring. The phenotype of cla4 ste20 double mutants identifies not only a role for Ste20-like protein kinases in morphogenesis, but also a novel step in bud development.

\section{Results}

Mutations in CLA4 and CLA10 cause a cytokinesis defect in cells lacking $C \ln 1$ and Cln2

To find additional regulators of Start, we set up a screen for yeast mutants unable to survive in the absence of the two $\mathrm{G}_{1}$ cyclins $\mathrm{Cln} 1$ and $\mathrm{Cln} 2$ (cla mutants-Cln activity dependent). Unexpectedly, no novel genes involved in all aspects of Start were found. We described previously the bud emergence mutants obtained in this screen and proposed that $C \ln 1$ and $C \ln 2$ have a role in the control of bud emergence (Cvrčková and Nasmyth 1993).

Other mutants, especially cla4 (two alleles characterized; allelic to erc10 described by Benton et al. 1993), cla6 (two alleles), and cla10 (five alleles), suffer from defects in cytokinesis, that is, at a very late stage of the cell cycle. This was surprising because $G_{1}$ cyclins are thought to act early. In the absence of $C \ln 1$ and $C \ln 2$, cla4, cla6, and cla10 mutant cells divide their nuclei and bud, but they cannot undergo cytokinesis (Fig. 1). Subsequent observations revealed that even cultures of the viable $\operatorname{cln} 1 \operatorname{cln} 2$ mutant contain cells with broad bud necks and cell clusters resulting from delayed cytokinesis. This further supports the idea that $C \ln 1$ and $C \ln 2$ have a role in bud development and cytokinesis in addition to the previously reported function in bud emergence; the apparent cytokinesis failure in cla4, cla6, and cla10 mutants could perhaps be a late consequence of an early defect.

\section{CLA10 is allelic to $\mathrm{CDC12}$}

The wild-type $C L A 10$ gene was cloned by complementation of cla10-1 mutation and sequenced (EMBL/GenBank accession no. X82498). The cloned DNA fragment was shown to be linked to the CLA10 locus. Sequence comparison revealed that $C L A 10$ is allelic to $C D C 12$ 
a

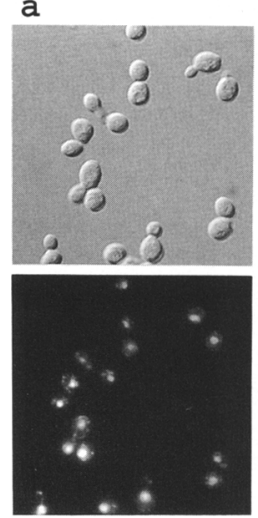

$C L A+$
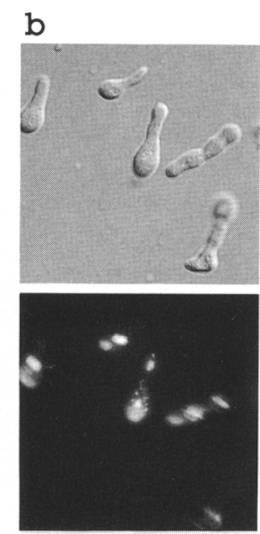

Cla4-1
C

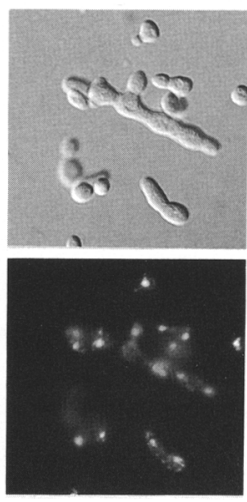

cla6-1

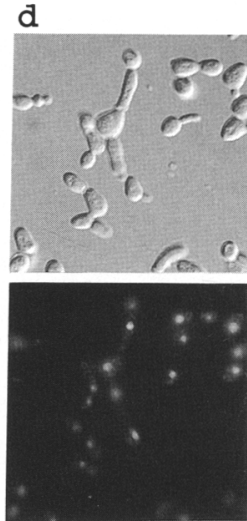

c1a10-1
Figure 1. cla4, clab, and cla10 mutants suffer from a cytokinesis defect in the absence of $C \ln 1$ and $C \ln 2$. (a) $c \ln 1 \mathrm{cln} 2$ cells carrying GAL::CLN1 (K3065) were grown exponentially in YEPGalRaff and transferred for $4 \mathrm{hr}$ into YEPDRaff to achieve Cln1 depletion. The following cultures were treated in the same manner: $|b| c \ln 1 \mathrm{cln} 2 \mathrm{cla} 4-1$ GAL::CLN1 (K3546) cells; (c) cln1 cln2 cla6-1 GAL::CLN1 (K5007) cells; (d) cln1 cln2 cla10-1 GAL::CLN1 (K3543) cells. (Top) Nomarski phase contrast; (bottom) DNA staining (DAPI).
(GenBank L16551), a member of the septin gene family that includes also the yeast genes $C D C 3, C D C 10$, $C D C 11$, several mammalian genes, and the Drosophila Pnut gene required for cytokinesis (Neufeld and Rubin 1994).

Yeast Cdc3, Cdc10, Cdc11, and Cdc12 (possibly together with other-yet unknown-proteins) form a ring of 10-nm filaments at the neck between the mother cell and its bud around the time of Start. Perturbation of the ring by a mutation in one of the septins causes a phenotype similar to that of $c \ln 1$ cln2 cla 10 mutants. $C D C 12$ is an essential gene (B. Haarer and J.R. Pringle, unpubl.); our mutants must thus be partial loss-of-function alleles. A possible explanation for the $c \ln 1 \mathrm{cln} 2$ cla 10 phenotype would be that phosphorylation of some protein associated with the septin ring by Cln1- or Cln2- activated Cdc28 kinase facilitates ring assembly and that this phosphorylation becomes essential if a component of the ring is damaged by mutation.

\section{CLA4 codes for a novel protein kinase}

We cloned the CLA4 gene by complementation of the cla4-1 mutation, confirmed that the cloned DNA is linked to $C L A 4$, and sequenced the gene. The minimal complementing fragment contained a single open reading frame. Northern analysis of RNA from a synchronous culture revealed that $C L A 4$ is transcribed throughout the cell cycle (data not shown). CLA4 (EMBL/GenBank accession no. X82499) encodes a protein of 842 amino acids, with a putative protein serine/threonine kinase domain on its carboxyl terminus and two conserved motifs in its amino-terminal part (Fig. 2). One of these motifs is the Pleckstrin homology $(\mathrm{PH})$ domain, shared by several proteins interacting with GTP-binding proteins and other components of signaling pathways (see Mustacchio et al. 1993). The PH domain can bind phosphatidylinositol-4,5-bisphosphate in vitro (Harlan et al. 1994). The other motif, flanking the carboxy-terminal end of the PH domain, is shared by two kinases whose overall structure is similar to that of Cla4: the mammalian brain-specific kinase Pak (Manser et al. 1994) and the yeast Ste20 kinase (Leberer et al. 1992; Ramer and Davis 1993). Neither Ste20 nor Pak contains a PH domain. In Cla4, the Pak/Ste20 homology region contains a good match to the sequence motif ISxPx ${ }_{4-6} \mathrm{HxxH}$ shared by several kinases associated with Rho-related small GTPases. In Pak, this region binds the GTP-bound form of two Rho-like proteins, Cdc42Hs and Racl (Manser et al. 1994); Cdc42Hs is a human homolog of the yeast Cdc42 GTPase required for bud emergence.

\section{CLA4 is a nonessential gene}

To study the role of $C L A 4$ in wild-type cells, we replaced the Cla4 kinase domain by the $L E U 2$ gene, producing the cla4::LEU2 allele (see Materials and methods). Diploid cells heterozygous for cla4::LEU2 were indistinguishable from the wild type with respect to colony growth and cell morphology. Haploid cla4::LEU2 cells derived by sporulation of this diploid were viable and grew at a rate comparable to wild-type haploids (data not shown), but they had grossly abnormal morphology. They produced rough colonies containing clusters of deformed cells apparently defective in cytokinesis; similar defects were seen in liquid media (Figs. 3 and 4, below). Homozygous cla4::LEU2 diploid cells grew more slowly than wild-type or heterozygous controls. We conclude that CLA4 is required for normal cell morphology and possibly for proper timing of cytokinesis.

Deletion of $C L A 4$ in cells lacking any single CLN gene did not cause any additional phenotype. Triple $c \ln 1 \mathrm{cln} 3$ cla4::LEU2 or $c \ln 2$ cln3 cla4::LEU2 mutants are viable, though they grow more slowly and have a more severe cytokinesis defect than cla 4 mutants. One could argue that the lethality of $\operatorname{cln} 1 \mathrm{cln} 2 \mathrm{cla} 4$ mutants results from a decrease in fitness owing to the combination of three mildly deleterious mutations. However, loss of Clb5 and Clb6, the pair of B-type cyclins involved in S-phase regulation, has as great an effect on growth rate and cell size as deletion of CLN1 and CLN2 (Schwob and Nasmyth 1993), but clb5 clb6 cla4::LEU2 mutants are viable. This 
Cvrčková et al.

Figure 2. Predicted structure of the $\mathrm{Cla} 4$ protein and sequence of the conserved domains. (O) The putative Cdc42-GTP binding site; CLA4-A and CLA4-B denote the parts of the protein used in the interaction assays (Fig. 3 ; Table 1). For the $\mathrm{PH}$ domain, alignment to representative members of the sequence family is shown (Mustacchio et al. 1993).
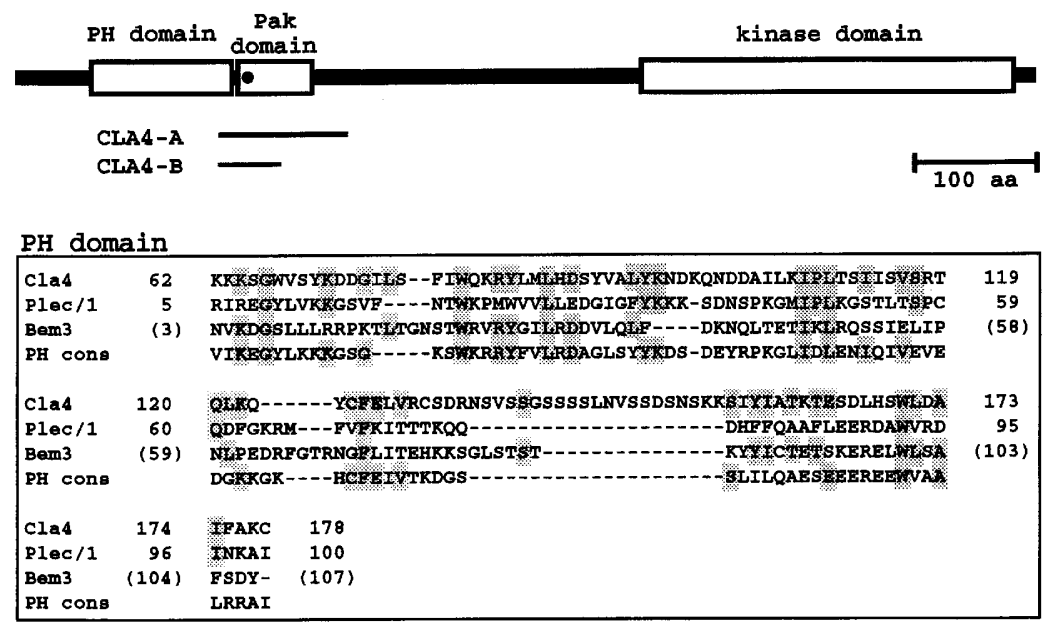

\begin{tabular}{|c|c|c|c|}
\hline $\mathrm{Cla4}$ & 184 & 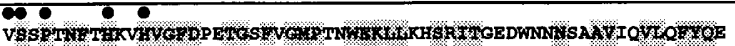 & 243 \\
\hline Ste20 & 337 & 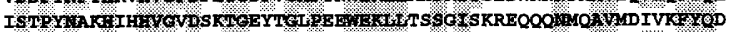 & 396 \\
\hline Pak & 75 & 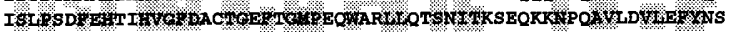 & 134 \\
\hline
\end{tabular}

\begin{tabular}{|c|c|c|c|c|}
\hline Clas & 517 & \multicolumn{2}{|c|}{ 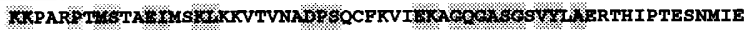 } & 576 \\
\hline ste20 & 591 & \multirow{2}{*}{\multicolumn{2}{|c|}{ 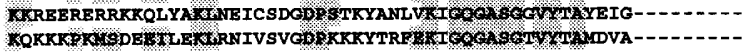 }} & 641 \\
\hline Pak & 240 & & & 290 \\
\hline clas & 577 & \multirow{2}{*}{\multicolumn{2}{|c|}{ 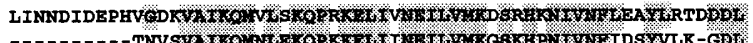 }} & 636 \\
\hline ste20 & 642 & & & 690 \\
\hline Pak & 291 & \multicolumn{2}{|c|}{ 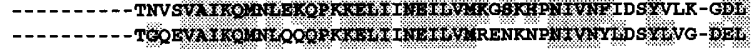 } & 339 \\
\hline clas & 637 & \multicolumn{2}{|c|}{ 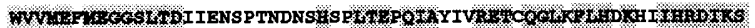 } & 696 \\
\hline ste20 & 691 & \multirow{2}{*}{\multicolumn{2}{|c|}{ 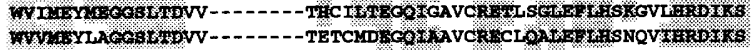 }} & $\mathbf{7 4 2}$ \\
\hline Pak & 340 & & & 391 \\
\hline clas & 697 & \multicolumn{2}{|c|}{ 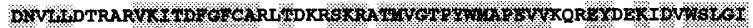 } & 756 \\
\hline ste20 & 743 & \multirow{2}{*}{\multicolumn{2}{|c|}{ 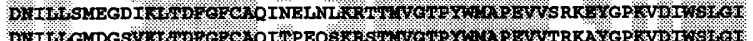 }} & B02 \\
\hline Pak & 392 & & & 451 \\
\hline Clas & 757 & \multicolumn{2}{|c|}{ 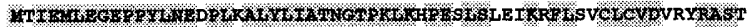 } & 816 \\
\hline Ste20 & 803 & \multicolumn{2}{|c|}{ 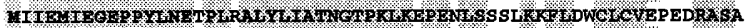 } & 862 \\
\hline Pak & 452 & \multicolumn{2}{|c|}{ 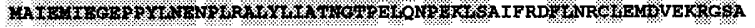 } & 511 \\
\hline Clas & 817 & 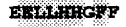 & 825 & \\
\hline ste20 & 863 & TERIArrDEYI & 871 & \\
\hline Pak & 512 & 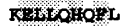 & 520 & \\
\hline
\end{tabular}

is consistent with $C \ln 1$ and $C \ln 2$ having a specific role in bud morphogenesis and cytokinesis.

\section{Physical and genetical interactions between Cla 4 and $\mathrm{Cdc} 42$}

The presence of a putative GTP-Cdc42-binding site in Cla4 suggests that in spite of the different mutant phenotypes, Cla4 and Cdc42 may be involved in the same process. Binding between Cdc42 and Cla4 could, for instance, be needed for localization or spatially restricted activation of the Cla4 kinase at the bud site, which is marked by Cdc42, and local activity of Cla 4 may be required for proper function of the septin ring. We therefore decided to test whether Cla4 could bind to GTP$\mathrm{Cdc42}$ in vitro.

We could not express full-length $\mathrm{Cla} 4$ as a glutathione $S$-transferase (GST) fusion protein in Escherichia coli, but two fragments of $\mathrm{Cla} 4$, containing the putative Cdc42-binding site, were successfully purified. Both frag- ments bind GTP-loaded yeast and human Cdc42 efficiently in overlay assays. The related yeast Rhol GTPase is not bound (Fig. 3). Yeast GTP-Cdc42 binds better to the Cla4 fragments than to the mammalian Pak kinase, whereas the converse is true for human GTP-Cdc42. No such difference was observed with another mammalian Cdc42-binding kinase, Ack (Manser et al. 1993).

Interaction between $\mathrm{Cla} 4$ and $\mathrm{Cdc} 42$ was also detected using the two-hybrid system in vivo (Table 1). No interaction was seen between full-length, normal Cdc42 and either full-length Cla4 or a fragment of Cla4 that bound Cdc42 in vitro (line 1). However, an interaction was found with a mutant $\mathrm{Cdc} 42$ that should be unprenylatable and hence less tightly (if at all) membrane associated (line 2). The interaction was stronger when Cdc42 also contained mutations inactivating its GTPase activity and thus locking it in the GTP-bound state /lines 3 and 4) and disappeared when Cdc42 contained a mutation believed to lock it in the GDP-bound state (line 5). To avoid high backgrounds observed with the unpreny- 
a

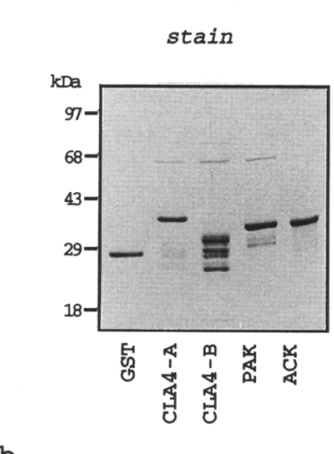

b

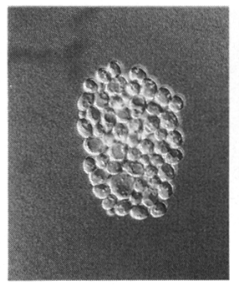

CLA4 CDC42

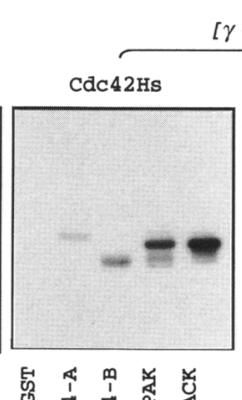

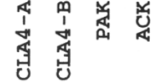

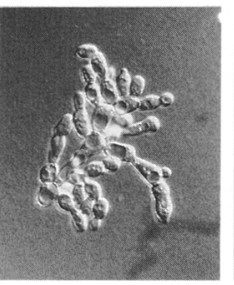

c1a4 CDC42 $\gamma^{32}$ P] GTP-p21 overlay
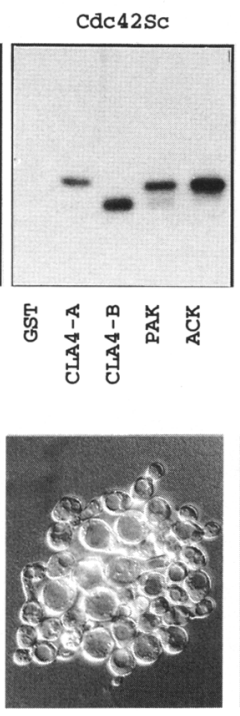

CLA4 CdC42

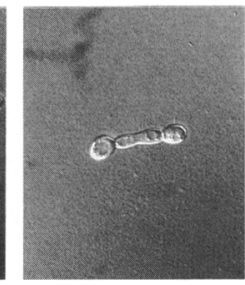

cla4 cdc42
Figure 3. (a) Cla4 binds Cdc42-GTP. (Left) Recombinant GST fusion proteins separated on a SDS-polyacrylamide gel and stained with Coomassie blue. CLA4-A corresponds to $\mathrm{Cla} 4$ residues 174-279, CLA4-B to Cla4 residues 174-222, PAK to Pak residues $69-150$, and ACK to Ack residues 499-570. CLA4-B corresponds to the minimal p21-binding domain described for Ack (Manser et al. 1993). (Middle and right) p2l overlay assays on parallel gels with the indicated recombinant p21 proteins. (b) cla4 and cdc42 mutations are synthetic lethal. Microcolonies grown from spores from a diploid (K5057) heterozygous for $c d c 42-1$ and cla4::LEU2 after $24 \mathrm{hr}$ on YEPD at $25^{\circ} \mathrm{C}$. latable Cdc42 (lines 2-4), the tests were repeated with the vectors reversed (lines 16-19). In this case, background values were low, and a weak but significant interaction was detected between full-length Cla4 and the GTPase-defective, unprenylatable Cdc42 (line 16). More striking results were obtained with the truncated $\mathrm{Cla} 4$ (line 17), where a very weak interaction was detected even with normal Cdc42. The interaction was $\sim 30$-fold stronger for the unprenylatable $\mathrm{Cdc} 42$ and another 2.6fold stronger for Cdc42 locked in the GTP-bound form. No interactions were detected between either full-length or truncated Cla4 and a variety of other small GTPases (lines 6-15).

We conclude that Cla4 directly interacts with $\mathrm{Cdc} 42$, that this interaction is specific for $\mathrm{Cdc} 42$ among the family of small GTPases, that the interaction is much stronger (and perhaps only occurs) with GTP-bound Cdc42, and that the interaction is mediated by a site within amino acids $174-294$ of Cla4p.

In Pak, the GTP-Cdc42-binding domain regulates autophosphorylation-mediated kinase activation. Cla4 could also be regulated by its interaction with GTP$\mathrm{Cdc42}$; that is, Cdc42 might have another role in cytokinesis in addition to its known function required for polarized cell growth. This second function might have escaped detection, because polarized cell growth is itself required for budding. Perturbation of the GTPase cycle of Cdc42 can cause a phenotype reminiscent of that caused by loss of Cla4. In our strain background, $c d c 42-1 \mathrm{mu}$ tant cells often produce elongated buds at the permissive temperature (Fig. 3). Some mutant alleles of $C D C 24$, a gene encoding the GDP/GTP exchange factor for Cdc42, produce elongated buds at semipermissive temperature (Sloat et al. 1981). Consistent with an interaction between Cla4 and Cdc42 in vivo is the finding that double cla 4 cdc42-1 mutants are inviable at the permissive tem- perature for $c d c 42-1$. We did not obtain any double mutants from 22 tetrads of a diploid strain heterozygous for cla4::LEU2 and cdc42-1. All 10 spores predicted to have the cla4 cdc42-1 genotype germinated and underwent one to four cell divisions, producing finally a microcolony of misshapen dead cells (Fig. 3).

\section{Cla4 and Ste20 share an essential function}

The similarity between Cla4 and Ste20 suggests that the two kinases might have overlapping functions. Because the loss of STE2O in one of our strain backgrounds (K1107) leads only to a decrease in mating efficiency but not to sterility (B. Stevenson, pers. comm.), we could obtain a diploid strain heterozygous for CLA4 and STE2O by mating. Dissection of 12 asci from this diploid yielded no viable double mutants. All nine spores predicted to be the double cla4 ste 20 mutants germinated, produced one to two elongated buds, and usually lysed within $24 \mathrm{hr}$; none of them divided. A function shared by $\mathrm{Cla} 4$ and Ste 20 is thus required at least in the first cell cycle after germination. To examine whether it is required also for the vegetative cell cycle, we constructed a regulated allele of CLA4 (MET::CLA4) by exchanging the chromosomal CLA4 promoter for the methionine-regulated MET3 promoter (see Materials and methods). MET::CLA4 STE20 cells are indistinguishable from wild type on media lacking methionine where the CLA4 gene is transcribed. On media containing methionine /where the gene is repressed), they acquire the shape typical for cla4 mutants only after several cell generations, suggesting that the Cla4 protein is rather stable. MET::CLA4 ste20 cells grow well in the absence of methionine, but most cells form only microcolonies consisting of 20-40 misshapen cells on media with methionine, indicating 
Table 1. Interaction between Cdc42 and Cla4 detected by the two-hybrid assay

\begin{tabular}{|c|c|c|c|c|}
\hline \multirow{2}{*}{$\begin{array}{l}\text { LexA-DBD } \\
\text { fusion (pEG202) }\end{array}$} & \multicolumn{4}{|c|}{ LexA-AD fusion (pJG4-5) } \\
\hline & $C L A 4$ & $C L A 4-A$ & MSB2 & none \\
\hline 1. $C D C 42$ & 1 & 5 & 4 & 2 \\
\hline 2. $C D C 42^{\mathrm{C} 188 \mathrm{~S}}$ & 248 & 129 & 41 & 40 \\
\hline 3. $C D C 42^{\mathrm{G} 12 \mathrm{~V} / \mathrm{Cl} 188 \mathrm{~S}}$ & 1280 & 876 & 262 & 323 \\
\hline 4. $C D C 42^{\mathrm{Q} 61 \mathrm{~L} / \mathrm{C} 188 \mathrm{~S}}$ & 1663 & 1382 & 205 & 311 \\
\hline 5. $C D C 42^{D 118 A / C 1885}$ & 20 & 10 & 10 & 6 \\
\hline 6. RHO1 & 5 & 3 & 7 & 7 \\
\hline 7. $\mathrm{RHO}^{\mathrm{C} 206 \mathrm{~S}}$ & 25 & 20 & 33 & 30 \\
\hline 8. RHO2 & 6 & 8 & 6 & 20 \\
\hline 9. $\mathrm{RHO}^{\mathrm{C} 188 \mathrm{~S} / \mathrm{C} 189 \mathrm{~S}}$ & 14 & 23 & 23 & 26 \\
\hline 10. RHO3 & 7 & 4 & 6 & 6 \\
\hline 11. $\mathrm{RHO}^{\mathrm{C} 228 \mathrm{~S}}$ & 1 & 11 & 14 & 10 \\
\hline 12. RHO4 & 7 & 5 & 39 & 7 \\
\hline 13. $R H O 4^{\mathrm{C} 288 \mathrm{~s}}$ & 17 & 50 & 97 & 69 \\
\hline 14. RSR1 & 2 & 4 & 10 & 5 \\
\hline 15. RAS2 & 2 & 4 & 6 & 4 \\
\hline
\end{tabular}

LexA-AD fusion (pJG4-5)

\begin{tabular}{|c|c|c|c|c|c|c|}
\hline & & & & & & \\
\hline & $C D C 42$ & $C D C 42^{\mathrm{C1885}}$ & $C D C 42^{\mathrm{G} 12 \mathrm{~V} / \mathrm{C} 188 \mathrm{~S}}$ & $C D C 42^{\mathrm{Q} 61 \mathrm{~L} / \mathrm{C} 188 \mathrm{~S}}$ & MSB2 & none \\
\hline 16. CLA4 & 2 & 5 & 110 & 138 & 3 & 6 \\
\hline 17. CLA4-A & 57 & 1777 & 4550 & 4777 & 15 & 5 \\
\hline 18. MSB2 & 2 & 7 & 3 & 3 & 2 & 2 \\
\hline 19. none & 20 & 18 & 26 & 18 & 17 & 17 \\
\hline
\end{tabular}

Interactions were tested first with Cdc42 and related GTPases fused to the LexA DNA-binding domain in plasmid pEG202, and Cla4 [or Msb2 (Bender and Pringle 1992) for negative control] fused to the activation domain in the plasmid pIG4-5 (lines 1-15). Selected

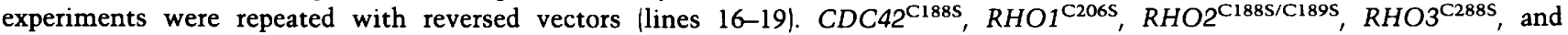
RHO4 ${ }^{\mathrm{C} 288 \mathrm{~S}}$ encode unprenylatable proteins. $C D C 42^{\mathrm{G} 12 \mathrm{~V}}$ and $C D C 42^{\mathrm{Q} 61 \mathrm{~L}}$ code for protines predicted to be locked in the GTP-bound form, whereas the product of $C D C 42^{\mathrm{D} 118 \mathrm{~A}}$ should be locked in the GDP-bound state (Ziman et al. 1991). The controls described as "none" are empty pJG4-5 or pEG202, respectively.

that Cla4 and Ste20 share a function essential for vegetative growth.

\section{Cla4 does not act through the pheromone signaling or protein kinase $C(\mathrm{PKCl})$ pathway}

Ste20 transduces the signal elicited by the binding of the mating pheromone to its receptor toward a protein $\mathrm{ki}$ nase cascade related to the mammalian mitogen-activated protein kinase (MAPK) pathway (for review, see Ammerer 1994). The pheromone response system consists of kinases encoded by STE11, STE7, and FUS3 or KSS1; the Ste5 protein (which is not a kinase) is also required for signal transduction, possibly at multiple steps. One explanation for the lethality of cla4 ste20 double mutants is that the Cla4 and Ste20 protein kinases share substrates whose phosphorylation is needed for cytokinesis. Alternatively, Cla4 might share a direct or indirect target with an element of the pheromone response system downstream of Ste20. If the latter were true, constitutive, Ste20-independent activation of the pheromone response pathway should abolish the requirement for Ste20 in cla4 mutants, and disruption of the pheromone response pathway downstream of STE2O may be as deleterious for the cla 4 mutants as the loss of Ste20 itself.

Low-level ectopic expression of the dominant hyperactivated STE11-279S allele constitutively activates pheromone response and is sufficient to restore mating to ste 20 mutants in a strain background where these are sterile (Stevenson et al. 1992). However, it does not affect the phenotype of MET::CLA4 ste20 mutants on media containing methionine. Furthermore, double cla 4 ste 5 and cla4 ste 11 mutants are viable. The essential function of Ste20 in cla 4 cells does not therefore require known components of the pheromone response pathway immediately downstream of Ste20.

The functional redundancy between Cla4 and Ste20 might be attributable to the ability of Ste20 to activate another MAPK-like kinase cascade. The essential protein kinase $C$ (PKC1)-dependent system, consisting of the Bck1, Mkk1/Mkk2, and Mpk1 kinases, is required for the maintenance of cell wall integrity. Constitutive activation of the PKC1 pathway by the dominant $B C K 1-20$ allele (Lee and Levin 1992) does not affect the phenotype of MET::CLA4 ste20 mutants on media containing methionine (data not shown); therefore, this system is unlikely to be involved in the essential function common to Cla4 and Ste20. 
Activation of the high osmolarity response (HOG) pathway may compensate for loss of Cla 4

Another MAPK-like kinase cascade known to function in vegetative yeast cells-the HOG (high osmolarity glycerol) response system-is required for proliferation on high osmolarity media. Mutants lacking either of the bottom two kinases of this cascade-Pbs2 or $\mathrm{Hog} 1$ - cannot accumulate intracellular glycerol nor transcribe some osmolarity-regulated genes nor undergo cytokinesis on high salt media (Brewster et al. 1993). The phenotype of cla4 mutants is reminiscent of the described defect of hog1 and pbs2 mutants on high salt media, suggesting that a Cla4-dependent mechanism and the $H O G$ system might have a similar role, the former being functional only on low salt media, the later in a high osmolarity environment.

If this were the case, increased salt concentration in the media might rescue the morphological defect caused by the loss of Cla4. It is therefore remarkable that cla4::LEU2 mutants acquire an almost wild-type shape in high salt media (Fig. 4). Disruption of either HOG1 or $P B S 2$ aggravates the morphological phenotype of cla4 on standard media and abolishes the rescue by salt (Fig. 4). However, the latter result should be interpreted cautiously, because single hog1 or pbs 2 mutants are already impaired under the same conditions. Nevertheless, our observations are consistent with the idea that the HOG pathway and Cla4 have common functions.

\section{Cla4 or Ste20 is required for proper function of the septin ring}

The phenotype of cla4 mutants and the isolation of $c d c 12$ mutants in the same genetic screen suggest that Cla4 may be needed for proper function of the septin ring. Additional support for this hypothesis comes from the finding that double cla4::LEU2 cdc12-1 mutants are inviable or at least severely impaired even at permissive temperature for the $c d c 12-1$ mutant: no viable double mutants were obtained in 19 tetrads from a diploid heterozygous for the two mutations. We thus decided to study the behavior of septins in cla4 mutants.

To examine the phenotype caused by the loss of the essential function of $\mathrm{Cla} 4$, we generated a thermosensitive allele of CLA4 (cla4-75) by PCR mutagenesis of the cloned gene and introduced it into a strain lacking CLA4 and STE2O. The resulting cla4-75 ste20 strain was thermosensitive for growth, exhibiting a uniform first cell cycle arrest with a phenotype similar to the original $c \ln 1$ cln 2 cla 4 mutant. To characterize this phenotype more thoroughly, we compared the progression of the cell cycle of CLA4 ste20 and cla4-75 ste 20 cells. $G_{1}$ cells were isolated by centrifugal elutriation and grown at $37^{\circ} \mathrm{C}$, the nonpermissive temperature for cla4-75. Inactivation of Cla4 in cla4-75 ste20 cells did not affect the timing of DNA replication, mitotic spindle formation or budding compared with the CLA4 ste20 strain (Fig. 5). However, buds formed at $37^{\circ} \mathrm{C}$ were malformed, resembling the protuberances or "shmoos" of yeast gametes preparing to
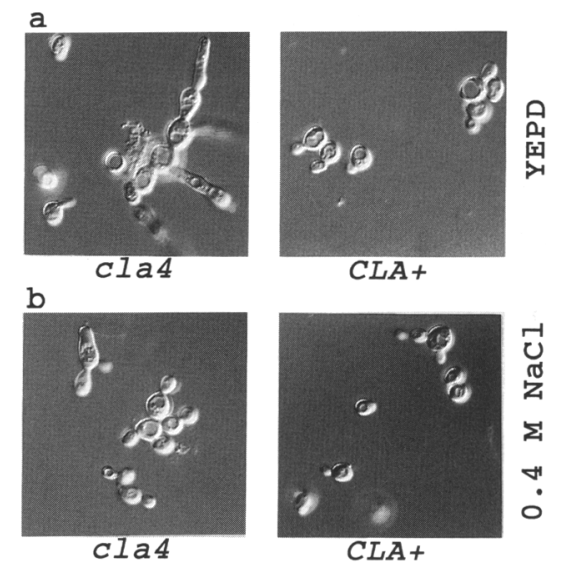

C

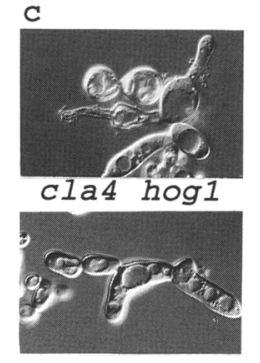

cla4 pbs2
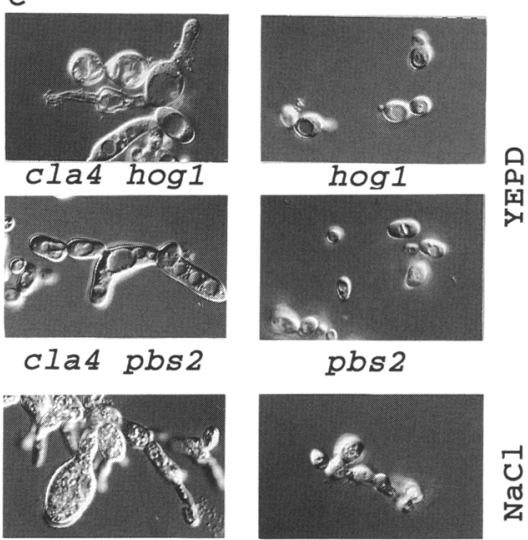

cla4 hog1

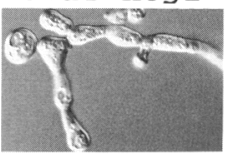

Cla4 pbs 2

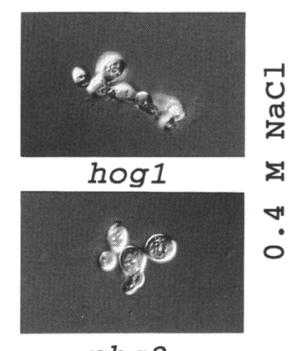

pbs2

Figure 4. (a) Loss of Cla4 causes a morphological defect. (Left) cla4::LEU2 (K3591); (right) wild-type (K699) cells grown in YEPD. $(b)$ This defect is compensated for under conditions inducing the HOG pathway. (Left) cla4::LEU2 (K3591); (right) wild-type (K699) cells grown in YEPD $+0.4 \mathrm{M} \mathrm{NaCl}$ (c) This rescue requires the HOG pathway. (Left) cla4::LEU2 hog1: :TRP1 (K4329) or cla4::LEU2 pbs2::URA3 (K4333) cells; (right) hog1::TRP1 (K4327) or pbs2::URA3 (K4331) cells grown in YEPD or YEPD + $0.4 \mathrm{M} \mathrm{NaCl}$.

mate (Fig. 6a). Immunofluorescent staining of the Cdc11 septin revealed that a septin ring forms in mutant cells at the same time and place (i.e., at the site of "bud/shmoo" emergence) as in ste20 cells that do not have any cytokinesis defect. However, at later stages the ring appears in most cases at the tip of the malformed bud rather than at a defined bud neck and often becomes diffuse (Fig. 6b). Whereas wild-type cells deposit new cell wall only on the bud side of the septin ring, cla 4 ste20 mutant cells grow new wall mostly if not exclusively on the mother side of the ring (Fig. 6c). Cortical actin localizes normally (i.e., toward the bud tip) in cla 4 ste20 cells, suggesting that at least some Cdc42-dependent events remain undisturbed in the double mutant (Fig. 7). In addition to the 


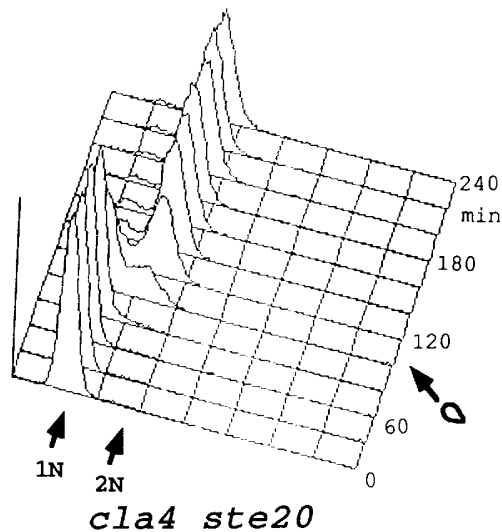

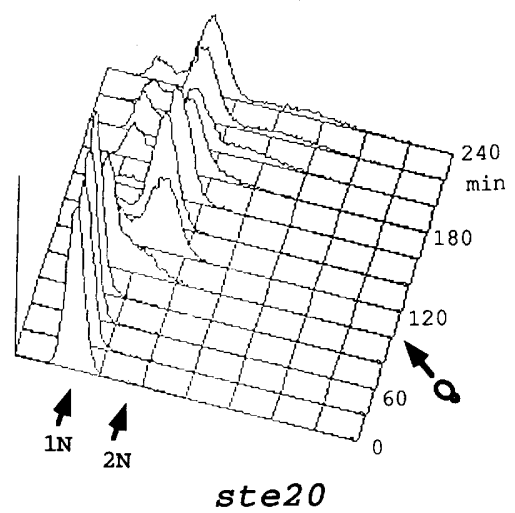

ste20

Figure 5. cla4-75 ste 20 cells (K4580) and CLA4 ste20 cells (K3621) were synchronized by centrifugal elutriation and released at $37^{\circ} \mathrm{C}$ (the restrictive temperature for cla4-75). DNA replication was followed by FACS analysis; fractions of unbudded cells, cells with mitotic spindles of various stages, and Cdcll-containing structures were determined microscopically. (a) cla4-75 ste 20 and CLA4 ste20 cells undergo DNA replication and acquire polarized shape at the same time larrows denote the time when half of the culture budded). (b) Initiation of DNA replication, local accumulation of Cdc11, budding, and mitotic spindle formation occur at a comparable cell size in mutant and control cells, whereas spindle elongation is delayed in the cla4-75 ste20 mutant.

b

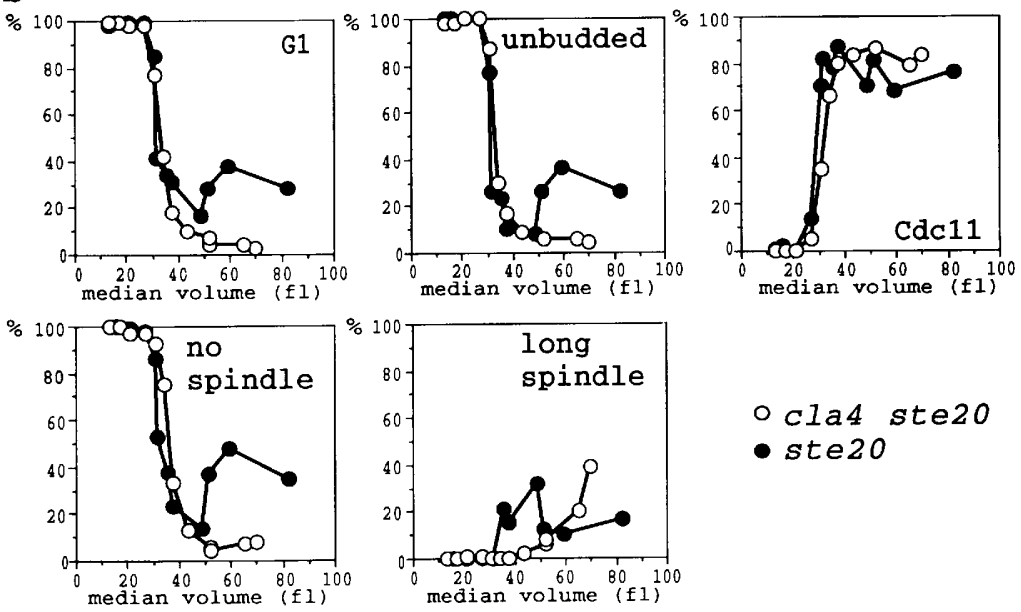

described phenotype, cla 4 ste20 mutants have a delay in mitotic spindle elongation: only about a third of the cells undergoes anaphase within $4 \mathrm{hr}$, and many of the others die and lyse as uninucleate cells (Fig. $5 b$; data not shown), suggesting that bud neck formation may not be the only event dependent on Cla4/Ste20. More likely, proper establishment of bud neck may be required for normal timing of nuclear division, as in the case of bud emergence (Lew and Reed 1995).

It is remarkable that cla4 ste20 cells assemble the septin ring but fail to develop the constriction ("neck") at the base of the bud. Septin ring assembly, although required, is therefore not sufficient for the establishment of a normal border between the mother cell and the bud. The phenotype of cla4-75 ste20 mutants seems to define a novel step in bud neck development: Cla4 and Ste20 share a function necessary for proper localization of cell surface growth with respect to the septin ring (or vice versa).

\section{Discussion}

$G_{1}$ cyclins have a role in cytokinesis

Cyclin-dependent protein kinases (Cdks) are responsible for the timing of cell cycle events in eukaryotic cells. Cytokinesis is one of the processes likely to be con- trolled by Cdks. The first step toward cytokinesis in yeast-budding-occurs in late $G_{1}$, simultaneously with the onset of DNA replication and spindle pole body duplication. These three events (often referred to as Start) are all regulated by a Cdk, Cdc28, associated with the $\mathrm{G}_{1}$ cyclins $C \ln 1, C \ln 2$, and $C \ln 3$. Mutants lacking one or two of the $G_{1}$ cyclins are viable, whereas the triple $c \ln 1$ cln2 cln3 mutant cannot undergo Start (Richardson et al. 1989). This, however, does not mean that the roles of the three $G_{1}$ cyclins are equivalent. The concentration of $\mathrm{Cln} 3$ remains constant throughout the cell cycle, while the abundance of $C \ln 1$ and $C \ln 2$ and the associated kinase activity oscillate during the cell cycle with a maximum around Start. Cln 3 is probably involved in the transcriptional activation of $C \ln 1$ and $C \ln 2$ in late $G_{1}$ (Cross and Tinkelenberg 1991; Dirick and Nasmyth 1991; Tyers et al. 1993; L. Dirick and K. Nasmyth, unpubl.) and in the activation of the B-type cyclins Clb5 and Clb6 that trigger DNA replication. The observed functional overlap of the $G_{1}$ cyclins results from the capability of $C \ln 1$ and $C \ln 2$ to induce their own-delayed-accumulation and the transcription of Clb5 and Clb6 in the absence of $\mathrm{Cln} 3$ and from the ability of Clb5 and $\mathrm{Clb} 6$ to provide the function of $C \ln 1$ and $C \ln 2$, albeit with a decreased efficiency (Epstein and Cross 1992; Schwob and Nasmyth 1993). 
The isolation of two genes involved in cytokinesis (CLA10/CDC12 and CLA4) in a screen for genes required for proliferation in the absence of $C \ln 1$ and $C \ln 2$
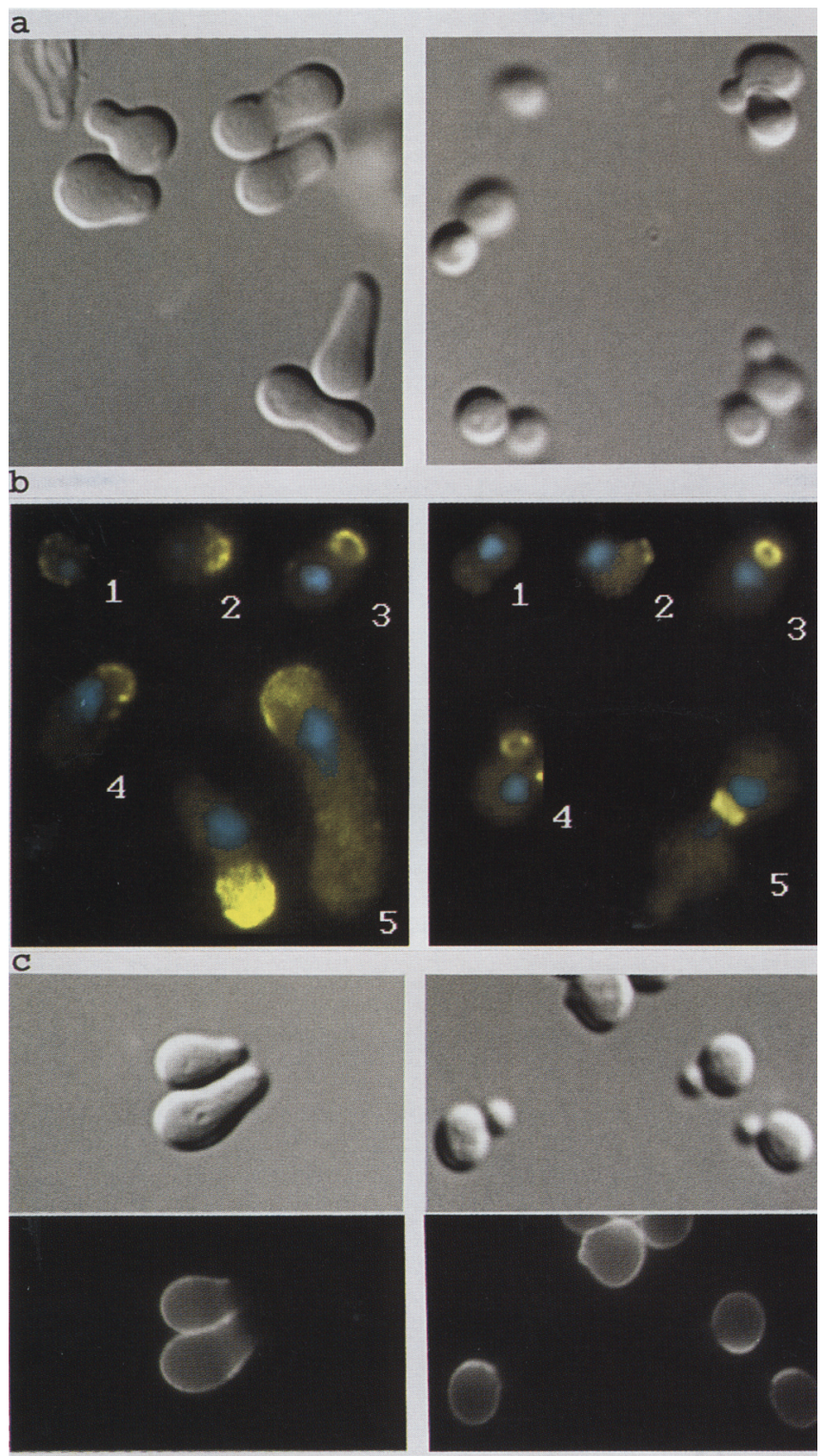

cla4-75 ste 20

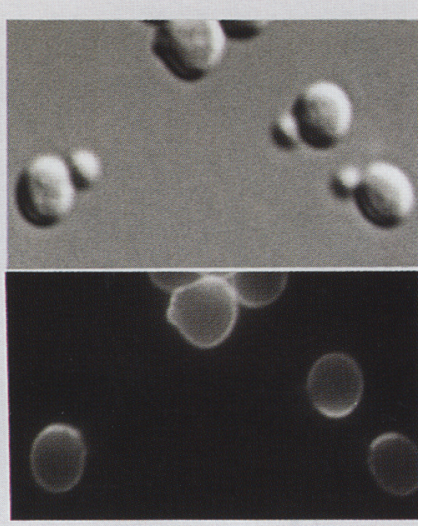

CLA4 ste 20

Figure 6. cla4-75 ste20 cells produce deformed buds with mislocalized septins at restrictive temperature and deposit new cell wall proximally to the septins. $(a)$ Exponential cultures of cla475 ste20 or CLA4 ste20 cells grown at $25^{\circ} \mathrm{C}$ in YEPD were shifted to $37^{\circ} \mathrm{C}$ for $3 \mathrm{hr}$ and observed by phase-contrast microscopy. (b) Typical cells from the synchronous cultures from Fig. 5., representing successive stages of the cell cycle (denoted by numbers). (Blue) DNA; (yellow) Cdc11. Because the staining requires the removal of cell wall, small buds may become difficult to see. (c) Exponential cultures of cla4-75 ste20 or CLA4 ste 20 cells grown at $25^{\circ} \mathrm{C}$ in YEPD were shifted to $37^{\circ} \mathrm{C}$ for $1 \mathrm{hr}$, the cell wall was labeled with fluorescein-conjugated Concanavaline A, and cells were grown for an additional $30 \mathrm{~min}$ at $37^{\circ} \mathrm{C}$ in the absence of the label and observed by fluorescence and phase-contrast microscopy. (Left) cla4-75 ste20 (K4580); (right) CLA4 ste20 (K3621).

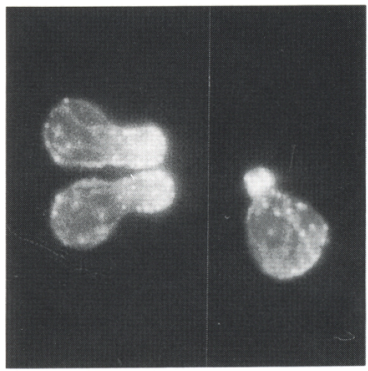

cla4-75 ste20

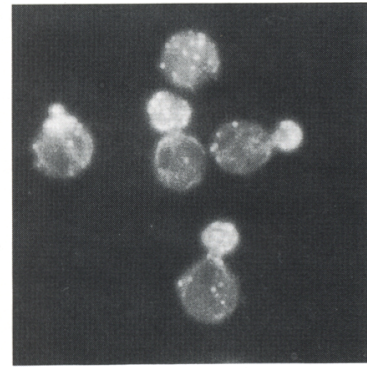

CLA4 ste20
Figure 7. Cla4 and Ste20 are not required for normal distribution of cortical actin. Exponential cultures of cla4-75 ste20 (K4580) or CLA4 ste20 (K3621) cells grown at $25^{\circ} \mathrm{C}$ in YEPD were shifted to $37^{\circ} \mathrm{C}$ for $3 \mathrm{hr}$ and fixed, and actin was stained with rhodamin-labeled phaloidin.

suggests that some proteins required for an early step toward cell division may be a direct substrate for the $\mathrm{Cdc} 28 / \mathrm{Cln}$ complex. The regulated step could be the establishment of the bud neck-an event that involves the assembly of a septin ring on the border between the mother cell and its bud; one of the components of the ring is encoded by $C D C 12$. In the absence of Clnl and $\mathrm{Cln} 2$, their function can be provided by another cyclin present at the same stage of the cell cycle (e.g., by Clb5 and Clb6), as long as all other proteins required for bud neck establishment and septin ring assembly are intact. If a component of the ring is damaged (as in $c d c 12 \mathrm{mu}-$ tants) or a regulatory event (e.g., phosphorylation of some protein by the protein kinase encoded by CLA4) is missing, $C \ln 1$ and $C \ln 2$ may become the only cyclins able to induce proper bud neck development.

We proposed previously a similar model suggesting a direct role for $C \ln 1$ and $C \ln 2$ in the first step toward budding - in bud site establishment and cell polarization (Cvrčková and Nasmyth 1993). This model can now be extended-also the next step in bud development, the formation of the border between the bud and its mother cell, appears to be controlled by $G_{1}$ cyclins. The apparent evolutionary conservation of cytokinesis mechanisms indicates that a similar control (perhaps involving different Cdk species) may be at work also in higher eukaryotes.

\section{Ste20-like kinases and the Cdc42 GTPase are required for cytokinesis}

Eukaryotes have evolved several ways to divide one cell into two. Most animal cells divide by cleavage, that is, by cytoskeleton-driven contraction of a part of the cell surface. Cells of higher plants form their septa "from within", by fusion of membrane vesicles carrying cell wall material to a location determined by cytoskeletal structures, producing the cell plate, which develops into a septum. Cytokinesis by budding, typical for yeasts, is a somewhat unusual variation of this theme. Nevertheless, similar mechanisms seem to be involved in budding and cleavage. Genes required for various steps of cytokinesis in the yeast Saccharomyces cerevisiae have been 
isolated and often shown to have relatives in higher eukaryotes.

One of the central molecules involved in the early steps toward yeast cytokinesis is the small GTPase Cdc42. In $S$. cerevisiae, $\mathrm{Cdc} 42$ is required for polarized cell growth both in the vegetative cell cycle (budding) and in the process of mating lasymmetric growth of gametesshmooing). Cdc42 cycles between the GTP- and GDPbound form; the putative guanine nucleotide exchange factor for Cdc42-Cdc24-is also required for directional growth (Zheng et al. 1994; for review, see Hall 1992).

Cdc42 is required for at least two events in bud development: One leads to actin polarization and subsequently to bud growth; the other leads to the deposition of a ring of 10-nm filaments (the septin ring) under the cytoplasmic membrane at the site of the future bud. Proteins related to components of the ring were found in animals, and a fruit fly homolog is required for cytokinesis (Neufeld and Rubin 1994).

Cdc42 homologs have also been found in higher eukaryotes. Biochemical studies identified a mammalian brain-specific protein kinase (Pak) that selectively binds to the GTP-bound form of Cdc42. Interestingly, Pak is related to the yeast Ste20 kinase, a component of the signal transduction mechanism required for differentiation of haploid cells into gametes in the presence of sexual pheromones and for pseudomycelial differentiation of diploid cells starved for nitrogen (Leberer et al. 1992; Liu et al. 1993; Ramer and Davis 1993). Until now, there was no indication that Ste20 might be involved in budding. It is therefore somewhat surprising that Ste20 also can, like Pak, bind Cdc42-GTP (Manser et al. 1994; Z.-S. Zhao, T. Leung, E. Manser, and L. Lim, in prep.; C. De Virgilio and J.R. Pringle, unpubl.).

We have isolated a novel yeast gene, CLA4, whose product is closely related to Ste 20 and Pak and specifically binds Cdc42-GTP both in vitro and in a two-hybrid in vivo assay. The interaction between Cla 4 and Cdc42 might be regulated in vivo, because truncated forms of Cla4 bind Cdc42-GTP better than a full-length protein. The observation that cla4 $c d c 42-1$ double mutants are lethal under conditions permissive for single mutants indicates that the interaction between $\mathrm{Cdc} 42$ and $\mathrm{Cla} 4$ may be significant in vivo. Binding to GTP-Cdc42 activates the mammalian Pak kinase (Manser et al. 1994); similarly, in yeast the interaction between Cla4 and GTP-Cdc42 might be needed for spatially restricted activation of the Cla4 kinase at the bud site, which is marked by Cdc42.

We found that Cla4 and Ste20 share an essential role in bud development. The previously observed lack of cell cycle-related phenotypes in ste20 mutants was apparently a result of a functional overlap between Ste20 and Cla4. Ste 20 interacts with the pheromone receptor-associated $\mathrm{G}$ protein and acts through a signaling pathway involving three protein kinases corresponding to the mammalian MAPK module. Unlike Ste20, other components of this pathway downstream of Ste20 are not required for cytokinesis in cells lacking Cla4. Ste20 therefore does not exert its essential function in cla 4 cells by activating the pheromone response pathway. However, some other MAPK-like kinase cascade activated by either Cla4 or Ste20 might be required for bud neck development. It is interesting that the nonlethal morphogenetic defect of cla4 mutants is compensated under conditions that induce another MAPK-like system, the HOG pathway, and this rescue seems to require the bottom two kinases of the HOG kinase cascade. Alternatively, some protein associated with the bud neck may have to be directly phosphorylated by either Cla4 or Ste20 to become functional.

\section{Ste20-like kinases are required for proper localization of cell growth with respect to the division plane}

Double cla4 ste20 mutants have a severe defect at an early stage of bud morphogenesis and cannot undergo cytokinesis. Normal bud neck development and cytokinesis require the establishment in late $G_{1}$ of a ring of septin-containing filaments defining the site of future cell division. Later on, all cell growth occurs on the bud side of the ring, whereas the mother cell ceases growing. The shape of cla4 ste20 mutants superficially resembles that of mutants defective in components of the septin ring. Moreover, mutants in $C D C 12$, which codes for one of the septins, were found in the same genetic screen. Cla4 or Ste20 may thus be required for proper localization or function of the septins. However, upon closer inspection, cla 4 ste 20 double mutants differ from septindefective mutants. $c d c 12-1$ cells under restrictive conditions maintain a border between the mother cell and the bud, despite gross morphological abnormalities and despite the absence of a detectable septin ring (Haarer and Pringle 1987). On the other hand, the septin ring assembles at the correct time and place in cla 4 ste20 mutant cells. However, it fails to stay at the bud neck and remains on the tip of the growing misshapen "bud" instead and usually becomes diffuse. Contrary to wild-type cells, new cell wall deposits proximally to the septin structure (i.e., on the mother cell side) in cla4 ste20 mutants.

These observations suggest that the assembly of the septin ring, albeit essential for cytokinesis, is not the only prerequisite for development of a normal bud neck. A separate event that requires a Ste20-like protein kinase (possibly regulated by $\mathrm{Cdc} 42$ and the $\mathrm{Cdc} 28 / \mathrm{Cln}$ complex) is needed to direct growth to a distinct part of the cell surface (Fig. 8). The growing part of the surface is normally enclosed by the septin ring, but the border between the growing and nongrowing surface apparently can form even in mutants defective in components of the ring itself, as documented by the phenotype of previously described cytokinesis mutants (cdc3, cdc10, $c d c 11$, and $c d c 12)$ that are defective in the septin ring. Mutants lacking Cla4 and Ste20 thus define a novel event in cell morphogenesis: They are impaired in the formation of a normal border separating the bud from the mother cell.

Septins, Ste20-like protein kinases, and Cdc42-like GTPases are evolutionarily conserved. Interestingly, 

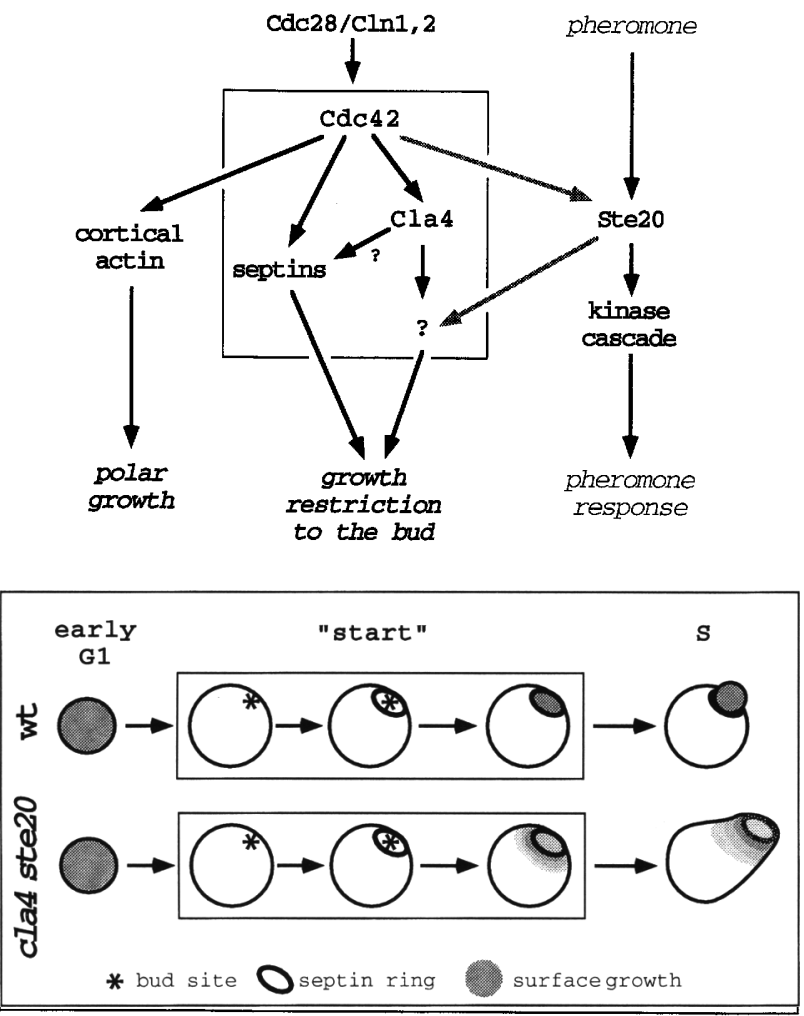

Figure 8. Cla4 and Ste20 share a role in establishing the border between mother cell and its bud, an event controlled by Cln1 and $\mathrm{Cln} 2$. The interaction between $\mathrm{Cla} 4$ and $\mathrm{Cdc} 42$ may be required for colocalization of active Cla4 kinase and the septin ring-two components contributing to the restriction of cell growth to the bud. mammalian homologs of these proteins are abundantly expressed in the brain, that is, in a tissue that contains rather few dividing cells. Could these proteins function in another process besides cytokinesis? The role of Cla4 and Ste 20 in yeast morphogenesis suggests the possibility that a similar mechanism might be involved also in spatial restriction of cell surface growth in other situations, including, perhaps, neural cell development.

\section{Materials and methods \\ Yeast strains and genetic techniques}

Genotypes of the strains not fully described in the text are listed in Table 2. The $\ln 1, \operatorname{cln} 2$, and ade3 alleles were described previously (Dirick and Nasmyth 1991; Cvrčková and Nasmyth 1993); hog $1:: U R A 3$ and pbs2::LEU2 were provided by $C h$. Schüller (University of Vienna, Austria), ste20::URA3 (Leberer et al. 1992) and the plasmid carrying the STE11-279S allelle under the GAL1-GAL10 promoter (Stevenson et al. 1992) were provided by B. Stevenson, $B C K 1-20$ on a centromeric plasmid was a gift from D. Levin (Johns Hopkins University, Baltimore, MD). Standard genetic techniques (Mortimer and Hawthorne 1969) and standard methods of DNA manipulation (Ausubel et al. 1987/ were used throughout. Yeast cells were transformed by the spheroplast or LiAc methods. Integrative transformations were verified by Southern blots. Yeast cells were grown aerobically at $30^{\circ} \mathrm{C}$ on YEP media (see Nasmyth and Dirick 1991) supplemented with $20 \mathrm{~g}$ /liter of the indicated sugars (D-glucose, Gal-galactose, Raff-raffinose), unless otherwise stated. Standard synthetic media supplemented with appropriate amino acids and nucleotides were used for experiments involving the methionine-regulated constructs; methionine was added to final concentration $2 \mathrm{mM}$ to repress the MET3 promoter. Plates containing 5-FOA (Boeke et al. 1987) were made as described by Nasmyth and Dirick (1991).

Table 2. Genotypes of yeast strains

\begin{tabular}{|c|c|c|}
\hline Strain & Genotype & Origin \\
\hline 699 & MATa, ade2-1, trp1-1, can1-100, leu2-3,112, his3-11,15, ura3,GAL,psi+, ssd1-d2(cla1) & W303 1A \\
\hline K1107 & MATa, HMLa, HMRa, ho-Bgal, ura3, ade2-1, ade6?, can1-100, met, his3, leu2-3,112, trp1-1, SSD1(CLA1) & $\begin{array}{l}\text { Dirick and } \\
\quad \text { Nasmyth (1991) }\end{array}$ \\
\hline K2726 & MATa, trp1, leu2, ura3, his3, ade2-1, ade3::HisG, cln1::HisG, cln2::del, SSD1, [YCp URA3 ADE3 spADH::CLN2] & $\begin{array}{l}\text { Cvrčková and } \\
\text { Nasmyth (1993) }\end{array}$ \\
\hline K2790 & MATa, trp1, leu2, ura3, ade2-1, ade3::HisG, cln1::HisG, cln2::del, SSD1, [YCp URA3 ADE3 spADH::CLN2] & $\begin{array}{l}\text { Cvrčková and } \\
\text { Nasmyth (1993) }\end{array}$ \\
\hline K3065 & MATa, trp1, leu2, ura3, ade2-1, ade3::HisG, cln1::HisG, cln2::de1, SSD1, [YCp URA3 LEU2 GAL::CLN1] & K2790 tfn \\
\hline K3535 & MATa, trp1, leu2, ura3, ade2-1, ade3::HisG, cln1::HisG, cln2::del, SSD1, cla10-1, [YCp URA3 ADE3 spADH::CLN2] & K2790 mut \\
\hline K3540 & MATa, trp1, leu2, ura3, ade2-1, ade3::HisG, cln1::HisG, cln2::de1, SSD1, cla4-1, [YCp URA3 ADE3 spADH::CLN2] & K2790 mut \\
\hline K3543 & MATa, trp1, leu2, ura3, ade2-1, ade3::HisG, cln1::HisG, cln2::del, SSD1, cla10-1, [YCp URA3 LEU2 GAL::CLN1] & K3535 tfn \\
\hline K3546 & MATa, trp1, leu2, ura3, ade2-1, ade3::HisG, cln1::HisG, cln2::del, SSD1, cla4-1, [YCp URA3 LEU2 GAL::CLN1] & \\
\hline K3591 & MATa, cla4::LEU2 & K699 bkg \\
\hline K3621 & MATa, bar1::HisG, ste20::URA3 & K1 107 bkg \\
\hline K3622 & 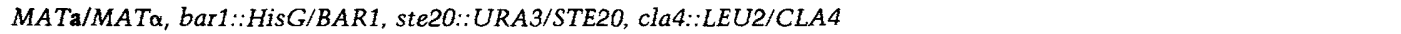 & $\mathrm{K} 1107 \mathrm{bkg}$ \\
\hline K4220 & MATa, bar1::HisG?, ste20::URA3, MET::CLA4 and HIS3 at cla4 & $\mathrm{K} 699 \mathrm{bkg}$ \\
\hline K4327 & MATa, hog1::TRP1 & K699 bkg \\
\hline K4329 & MATa, cla4::LEU2, hog1::TRP1 & K699 bkg \\
\hline K4331 & MATa, pbs2::URA3 & K699 bkg \\
\hline K4333 & MATa, cla4::LEU2, pbs2::URA3 & K699 bkg \\
\hline K4580 & MATa, cla4::LEU2, ste20::URA3, [YCp TRP1 cla4-75] & K3622 tfn spore \\
\hline K5005 & MATa, trp1, leu2, ura3, his3, ade2-1, ade3::HisG, cln1::HisG, cln2::del, SSD1, cla6-1, [YCp URA3 ADE3 spADH::CLN2] & K2726 mut \\
\hline K5007 & MATa, trp1, leu2, ura3, his3, ade2-1, ade3::HisG, cln1::HisG, cln2::del, SSD1, cla6-1, [YCp URA3 LEU2 GAL::CLN1] & K5005 tfn \\
\hline K5057 & MATa/MATa, CDC42/cdc42-1, CLA4/cla4::LEU2 & K699 bkg \\
\hline
\end{tabular}

Plasmid-borne markers are enclosed in square brackets. (tfn) The strain was obtained by transformation of the given parent; (bkg) it was derived from the given genetic background (and carries the same genetic markers unless stated otherwise) by multiple transformations and crosses of isogenic strains; (mut) an EMS-induced mutant. 


\section{Isolation of CLA10 and CLA4}

Wild type CLA10/CDC12 and CLA4 were cloned by complementation of cla10-1 and cla4-1 mutants, respectively. The cloning strategy, the genomic library used, and the sequencing procedure were as described (Cvrčková and Nasmyth 1993). For CLA10 isolation, 24,000 library transformants yielded $10 \mathrm{com}$ plementing clones. A $2.94-\mathrm{kb}$ region shared by all of them was sequenced. For CLA4, six clones complementing cla4-1 were found among 20,000 library transformants; additional CLA4 clones were found as suppressors of the cla6-2 mutation in an attempt to clone CLA6. A 3.86-kb fragment including the region shared by all plasmids complementing cla $4-1$ was sequenced.

\section{Linkage analysis}

To demonstrate linkage between cloned DNA fragments and the original cla mutations, we introduced the LEU2 marker close to the cloned loci in a diploid homozygous for the $\operatorname{cln} 1$ cln2 mutations and heterozygous for the CLA gene of interest. The strain carried plasmid-borne $C L N 2$ linked to the colony color marker $A D E 3$, so that segregation of the cla mutation in tetrads could be scored (Cvrčková and Nasmyth 1993). After sporulation of the marked strains, the $C L A^{+}$phenotype in both cases cosegregated with the LEU2 marker in at least 32 tetrads. The CLA loci were marked by a YIplac128 /Gietz and Sugino $1988)$ derivative containing a library insert complementing the cla mutation $(2.94 \mathrm{~kb}$ for CLA10; $5.3 \mathrm{~kb}$ for CLA4).

\section{Sequence comparisons}

The search for CLA10 and CLA4 homologs in the GenBank and EMBL data bases was done by the automated BLAST service at the National Center of Biological Information, USA /Altschul et al. 1990). The protein sequence alignment was constructed using the MACAW program (Schuler et al. 1991).

\section{Detection of Cla4/p21-GTP binding by an in vitro overlay assay}

To produce in-frame CLA4/GST fusions, DNA fragments corresponding to $C L A 4$ codons $174-279$ (for construct A) and 174 222 (for construct B) were amplified by PCR so that BamHI and $X$ oI sites were introduced at the $5^{\prime}$ and $3^{\prime}$ ends of the PCR products, respectively, and cloned into the $\mathrm{BamHl}-\mathrm{Xhol}$ sites of pGEX 4T-1 (Pharmacia). GST fusion proteins were purified from E. coli, separated on SDS-polyacrylamide gels, and transferred to membranes, and overlay assays were performed with $\left[\gamma^{-32} \mathrm{P}\right]$ GTP-loaded recombinant $\mathrm{p} 21 \mathrm{~s}$ as described (Manser et al. 1994), with minor modifications.

\section{Detection of Cla4/p21-GTP binding by an in vivo two-hybrid assay}

The two-hybrid assay was performed as described (Gyuris et al. 1993; Fields and Sternglanz 1994). To fuse various GTPases to the LexA DNA-binding domain (DBD) in pEG202, yeast CDC42 (Johnson and Pringle 1990), CDC42C188S (Ziman et al. 1991), RHO1 and RHO2 (Madaule et al. 1987), RHO3 and RHO4 (Matsui and Toh-e 1992; YKR055W, accession no. Z28280, MIPS), RSR1 (Bender and Pringle 1989), and RAS2 (Powers et al. 1984) full-length coding sequences were amplified by PCR with cloned genes as templates, and appropriate restriction sites were introduced with the primers. The mutant genes $C D C 42^{\mathrm{G} 12 \mathrm{~V} / \mathrm{C} 188 \mathrm{~S}}, C D C 42^{\mathrm{Q} 61 \mathrm{~L} / \mathrm{C} 188 \mathrm{~S}}, C D C 42^{\mathrm{D} 118 \mathrm{~A} / \mathrm{Cl} 188 \mathrm{~S}}$ RHO1 $1^{\mathrm{C} 206 \mathrm{~S}}, \mathrm{RHO} 2^{\mathrm{C} 188 \mathrm{~S} / \mathrm{C} 189 \mathrm{~S}}, \mathrm{RHO} 3^{\mathrm{C} 228 \mathrm{~s}}$, and $\mathrm{RHO} 4^{\mathrm{C} 288 \mathrm{~S}}$ were amplified using cloned $C D C 42^{\mathrm{G} 12 \mathrm{v}}, C D C 42^{\mathrm{Q} 61 \mathrm{~L}}$, $C D C 42^{D 118 A}$ (Ziman et al. 1991), or wild-type RHO genes as templates and reverse primers that specifically introduced the C-S mutations as well as an Xhol site downstream of the stop codon. The PCR products were cloned at the EcoRI-Xhol sites (all but RSR1) or at the BamHI-XhoI sites (RSR1) of pEG202. To fuse Cla4 or its fragment Cla4-A to the LexA DBD in pEG202, the full-length and partial (amino acids 174-294) CLA4 sequences were amplified by PCR as above. The PCR products were cloned at the EcoRI-Ncol sites (CLA4) or at the EcoRI$X$ hol sites (CLA4-A) of pEG202. All constructs except pEG202Rsrl contain 2 additional amino acids (EF), pEG202-Rsrl contains 5 amino acids (EFPGI) between the LexA DBD and the first amino acid of the fused protein $(\mathrm{M}$ for all but Rsrl and Cla4- $\mathrm{A}$; $\mathbf{R}$, corresponding to the second residue, for Rsrl, I, corresponding to residue 174, for Cla4-A). All constructs except pEG202Cla4-A use the original stop codons of the fused genes; pEG202Cla4-A uses a stop codon immediately downstream of the polylinker.

To fuse the various proteins to the activation domain (AD) in pJG4-5, the desired sequences were amplified by PCR as above and cloned into the EcoRI and XhoI sites of pJG4-5 or (for CLA4) into the EcoRI and NcoI sites of a pJG4-5 derivative with an Ncol site in its polylinker.

Strain EGY48 containing the LexAop-lacZ reporter plasmid pSH18-34 was cotransformed either with pEG202 or a pEG202 derivative expressing a LexA-DBD fusion and with pJG4-5 or a pJG4-5 derivative expressing an $\mathrm{AD}$-fusion protein. $\beta$-Galactosidase activities were measured in cultures grown for $16 \mathrm{hr}$ at $30{ }^{\circ} \mathrm{C}$ in minimal medium with $2 \%$ galactose and $1 \%$ raffinose. The average values from three to six different isolates of each strain (in Miller units) are reported.

\section{Construction of the cla4 disruption}

To disrupt CLA4 by one-step gene replacement, CLA4 was cloned into pUC19 and the internal SalI-XhoI fragment was replaced by wild-type $L E U 2$. The resulting disruption allele was used to transform a wild-type diploid strain (isogenic to K699 or K1107); haploid cla4 segregants were obtained after sporulation.

\section{Construction of the conditional lethal MET::CLA4 ste20 strain}

For construction of the methionine-repressible MET::CLA4 allele, an NdeI site was introduced by PCR at the ATG start codon of $C L A 4$, which was then fused to the MET3 promoter cloned as a SalI-NdeI fragment in the $\mathrm{pICl9H}$ vector (Mountain and Korch 1991; A. Amon, pers. comm.); the HIS3 marker on a $B a m H I-X h o I$ fragment was inserted upstream of the promoter, and a fragment from the CLA4 locus corresponding to bases $1-606$ of the presented sequence was cloned $5^{\prime}$ from HIS3. The resulting construct was used to replace the endogenous CLA4 promoter in a wild-type (K699) yeast strain by HIS3 and the $M E T 3$ promoter fused to the $C L A 4$ coding sequence. The transformed strain was crossed to a ste20::URA3 mutant (K3621) transformed with a plasmid carrying a hyperactivated STE11$279 S$ allele under the control of the GAL1-10 promoter. The basal level of STE11-279S transcription on glucose media is sufficient for Ste20-independent mating in this strain (G. Ammerer, pers. comm.). The plasmid was eliminated from the diploid, and double MET::CLA4 ste20 mutants were obtained by tetrad dissection on methionine-free media.

Isolation of thermosensitive alleles of CLA4 and construction of the thermosensitive cla4 ste20 strain

A DNA fragment corresponding to bp 471-3500 of the CLA4 sequence and sufficient to complement cla4-1 was amplified by 
mutagenic PCR (Amon et al. 1993). A library of PCR products in YCplac22 (Gietz and Sugino 1988) was screened for plasmids that suppress the lethality of MET::CLA4 ste20 (K4220) cells in the presence of methionine at $25^{\circ} \mathrm{C}$ but not at $37^{\circ} \mathrm{C}$. Four such clones found among 18,000 transformants were shown to be thermosensitive for the ability to rescue growth of $c \ln 1 \operatorname{cln} 2$ cla4-1 GAL::CLN1 (K3546) cells on glucose. One of the mutant alleles-cla4-75-was chosen for further study. To obtain a temperature-sensitive cla4-75 ste20 strain, a plasmid carrying cla4-75 was introduced into a diploid (K3622) heterozygous for CLA4 and STE20, and haploids were isolated by tetrad dissection.

\section{Synchronous cultures}

Cells were grown at $25^{\circ} \mathrm{C}$ in YEPRaff and synchronized by centrifugal elutriation as described (Schwob and Nasmyth 1993). Elutriated $\mathrm{G}_{1}$ cells were inoculated into YEPD medium at $37^{\circ} \mathrm{C}$ and followed over the period of $4 \mathrm{hr}$, determining periodically the fraction of budded cells (microscopically) and cell size (using the CASYl apparatus, Schärfe Systems $\mathrm{GmbH}$ ) and taking samples for immunofluorescence staining and for the analysis of DNA content. The DNA content was measured on a BectonDickinson FACScan analyzer as described (Epstein and Cross 1992; Lew et al. 1992). For quantitative evaluation of microscopy data, at least 100 cells were counted for each sample and characteristic.

\section{Fluorescence microscopy}

For in situ immunofluorescence, cells were fixed with $3.7 \%$ formaldehyde for $30 \mathrm{~min}$, converted to spheroplasts, and stained as described (Nasmyth et al. 1990) except that the cell wall was digested at $\mathrm{pH} 7.4$; to visualize nuclei, cells were stained with DAPI. Actin was stained with rhodamin-conjugated phalloidin according to Hašek et al. (1987). For staining of Cdc11, a rabbit polyclonal antibody (Ford and Pringle 1991) and a FITC-labeled goat anti-rabbit antibody (Calbiochem) were used. To localize the new cell wall, the following method (Porro and Srienc 1995) was used: One-milliliter aliquots of an exponentially growing culture in YEPD medium were centrifuged, and cells were washed with minimal raffinose medium and resuspended in $0.05 \mathrm{ml}$ of the same medium with $0.12 \mathrm{mg} / \mathrm{ml}$ of fluoresceinconjugated concanavaline A (Sigma). After $4 \mathrm{~min}$, cells were washed twice with minimal raffinose medium, diluted into 1 $\mathrm{ml}$ of YEPD, incubated for $30 \mathrm{~min}$ to allow growth of unstained cell wall, fixed as above, and observed. Cells were photographed using either a standard camera or a CCD videocamera connected to the microscope.

\section{Acknowledgments}

We thank G. Schaffner, I. Botto, and R. Kurzbauer for sequencing and primer synthesis; J. Wimmer for help cloning CLA4; $\mathrm{A}$. Pichová for help with actin staining; J. Fares for initial immunolocalization experiments; F. Srienc for advice on cell wall labeling; G. Ammerer, A. Bender, D. Johnson, D. Levin, Y. Matsui, G. Paravini, Ch. Schüller, and B. Stevenson for strains and plasmids; H. Tkadletz for photography; and L. Lim and members of the Nasmyth, Pringle, Lim, Ammerer, and Schuster groups for helpful comments throughout the course of this work. This work has been supported by the Austrian Industrial Research Promotion Fund, the National Institutes of Health (grant GM 31006), the L. \& Th. LaRoche Stiftung, the CibaGeigy-Jubilaeums-Stiftung, and the Glaxo-Singapore Research Fund.
The publication costs of this article were defrayed in part by payment of page charges. This article must therefore be hereby marked "advertisement" in accordance with 18 USC section 1734 solely to indicate this fact.

\section{References}

Altschul, S.F., W. Gish, W. Miller, E.W. Myers, and D.J. Lipman. 1990. Basic local alignment search tool. I. Mol. Biol. 215: 403-410. Ammerer, G. 1994. Sex, stress and integrity: The importance of MAP kinases in yeast. Curr. Opin. Genet. Dev. 4: 90-95.

Amon, A., M. Tyers, B. Futcher, and K. Nasmyth. 1993. Mechanisms that help the yeast cell cycle clock tick: G2 cyclins transcriptionally activate $\mathrm{G} 2$ cyclins and repress $\mathrm{G} 1$ cyclins. Cell 74: 993-1007.

Ausubel, F.M., R. Brent, R.E. Kingston, D. Moore, J.A. Smith, J.G. Seidman, and K. Struhl, ed. 1987. Current protocols in molecular biology. Wiley, New York.

Bender, A. and J.R. Pringle. 1989. Multicopy suppression of the cdc24 budding defect in yeast by CDC42 and three newly identified genes including the ras-related gene RSR1. Proc. Natl. Acad. Sci. 86: 9976-9980.

- 1992. A Ser/Thr-rich multicopy suppressor of a $c d c 24$ bud emergence defect. Yeast 8: 315-323.

Benton, B.K., A.H. Tinkelenberg, D. Jean, S.D. Plump, and F.R. Cross. 1993. Genetic analysis of $\mathrm{Cln} / \mathrm{Cdc} 28$ regulation of cell morphogenesis in budding yeast. EMBO J. 12: 52675275.

Boeke, J.D., J. Trueheart, G. Natsoulis, and G.R. Fink. 1987. 5-fluoroorotic acid as a selective agent in yeast molecular genetics. Methods Enzymol. 154: 164-175.

Brewster, J.L., T. de Valoir, N.D. Dwyer, E. Winter, and M.C. Gustin. 1993. An osmosensing signal transduction pathway in yeast. Science 259: 1760-1763.

Byers, B. and L. Goetsch. 1976. A highly ordered ring of membrane-associated filaments in budding yeast. $/$. Cell Biol. 69: 717-721.

Chant, J. 1994. Cell polarity in yeast. Trends Genet. 10: 328333.

Cross, F. and A.H. Tinkelenberg. 1991. A potential positive feedback loop controlling CLN1 and CLN2 gene expression at the start of the yeast cell cycle. Cell 65: 875-883.

Cvrčková F. and K. Nasmyth. 1993. Yeast Gl cyclins CLN1 and CLN2 and a GAP-like protein have a role in bud formation. EMBO /. 12: 5277-5286.

Dirick, L. and K. Nasmyth. 1991. Positive feedback in the activation of G1 cyclins in yeast. Nature 351: 754-757.

Epstein, C.B. and F.R. Cross. 1992. CLB5: A novel B cyclin from budding yeast with a role in S phase. Genes \& Dev. 6: 16951706. Fields, S. and R. Sternglanz. 1994. The two-hybrid system: An assay for protein-protein interactions. Trends Genet. 10: 286-292.

Ford, S.K. and I.R. Pringle. 1991. Cellular morphogenesis in the Saccharomyces cerevisiae cell cycle: Localization of the $C D C 11$ gene product and the timing of events at the budding site. Dev. Genet. 12: 281-292.

Gietz, R.D. and A. Sugino. 1988. New yeast-Escherichia coli shuttle vectors constructed with in vitro mutagenized yeast genes lacking six-base pair restriction sites. Gene 74: 527534.

Gyuris, J., E. Golemis, H. Chertkov, and R. Brent. 1993. Cdil, a human GI and S phase protein phosphatase that associates with cdk2. Cell 75: 791-803.

Haarer, B.K. and J.R. Pringle. 1987. Immunofluorescence local- 
ization of the Saccharomyces cerevisiae CDC12 gene product to the vicinity of the 10-nm filaments in the mother-bud neck. Mol. Cell. Biol. 7: 3678-3687.

Hall, A. 1992. Ras-related GTPases and the cytoskeleton. Mol. Biol. Cell 3: 475-479.

Harlan, J.E., P.J. Hajduk, H.S. Yoon, and S.W. Fesik. 1994. Pleckstrin homology domains bind to phosphatidylinositol-4,5 bisphosphate. Nature 371: 168-170.

Hašek, J., I. Rupeš, J. Svobodová, and E. Streiblová. 1987. Tubulin and actin topology during zygote formation of Saccharomyces cerevisiae. J. Gen. Microbiol. 133: 3355-3363.

Johnson, D.I. and J.R. Pringle. 1990. Molecular characterization of $C D C 42$, a Saccharomyces cerevisiae gene involved in the development of cell polarity. I. Cell Biol. 111: 143-152.

Johnson, D.I., J.M. O'Brien, and C.W. Jacobs. 1990. Isolation and sequence analysis of $C D C 43$, a gene involved in the control of cell polarity in Saccharomyces cerevisiae. Gene 90: 9398.

Kim, B.H., B.K. Haarer, and J.R. Pringle. 1991. Cellular morphogenesis in the Saccharomyces cerevisiae cell cycle: Localization of the $C D C 3$ gene product and the timing of events at the budding site. I. Cell Biol. 112: 535-544.

Leberer, E., D. Dignard, D. Harcus, D.Y. Thomas, and M. Whiteway. 1992. The protein kinase homologue Ste20p is required to link the yeast pheromone response $G$ protein bg subunits to downstream signalling components. EMBO J. 11:48154824.

Lee, K.S. and D.E. Levin. 1992. Dominant mutations in a gene encoding a putative protein kinase $(B C K 1)$ bypass the requirement for a Saccharomyces cerevisiae protein kinase $\mathrm{C}$ homolog. Mol. Cell. Biol. 12: 172-182.

Lew, D.J., and S.I. Reed. 1993. Morphogenesis in the yeast cell cycle: Regulation by $\mathrm{Cdc} 28$ and cyclins. I. Cell Biol. 120: $1305-1320$.

- 1995. A cell cycle checkpoint monitors cell morphogenesis in budding yeast. $J$. Cell Biol. 129: 739-749.

Lew, D.J., N.J. Marini, and S.I. Reed. 1992. Different G1 cyclins control the timing of cell cycle commitment in mother and daughter cells of the budding yeast $S$. cerevisiae. Cell 69: $317-327$

Liu, H., C.A. Styles, and G.R. Fink. 1993. Elements of the yeast pheromone response pathway required for filamentous growth in diploids. Science 262: 1741-1744.

Madaule, P., R. Axel, and A.M. Myers. 1987. Characterization of two members of the rho gene family from the yeast Saccharomyces cerevisiae. Proc. Natl. Acad. Sci. 84: 779-783.

Manser, E., T. Leung, H. Salihuddin, L. Tan, and L. Lim. 1993. A non-receptor tyrosine kinase that inhibits the GTPase activity of $\mathrm{p} 21^{\text {cdc42 }}$. Nature 363: 364-367.

Manser, E., T. Leung, H. Salihuddin, Z.S. Zhao, and L. Lim. 1994. A brain serine/threonine protein kinase activated by Cdc42 and Racl. Nature 367: 40-46.

Matsui, Y. and A. Toh-e. 1992. Isolation of two novel ras superfamily genes in Saccharomyces cerevisiae. Gene 114: 43-49.

Mortimer, R.K. and D.C. Hawthorne. 1969. Yeast genetics. In The yeasts, volume 1 (ed. A.M. Rose and J.S. Harrison), pp. 385-460. Academic Press, New York.

Mountain, H.A. and C. Korch. 1991. TDH2 is linked to MET3 on chromosome X of Saccharomyces cerevisiae. Yeast 7: 873880.

Mustacchio, A., T. Gibson, P. Rice, J. Thompson, and M. Saraste. 1993. The PH domain: A common piece in the structural patchwork of signalling proteins. Trends Biochem. Sci. 18: $343-348$.

Nasmyth, K. 1993. Control of the yeast cell cycle by the Cdc28 protein kinase. Curr. Opin. Cell Biol. 5: 166-179.
Nasmyth, K. and L. Dirick. 1991. The role of SWI4 and SWI6 in the activity of Gl cyclins in yeast. Cell 66: 995-1013.

Nasmyth, K., G. Adolf, D. Lydall, and A. Seddon. 1990. The identification of a second cell cycle control on the $\mathrm{HO}$ promoter in yeast: Cell cycle regulation of SWI5 nuclear entry. Cell 62: 631-647.

Neufeld, T.P. and G.M. Rubin. 1994. The Drosophila peanut gene is required for cytokinesis and encodes a protein similar to yeast putative bud neck filament proteins. Cell 77: 371379.

Ohya, Y., C.E. Trueblood, and Y. Anraku. 1995. Callp. In Guidebook to the small GTPases (ed. M. Zerial and L. Huber). Oxford University Press, Oxford, UK. (In press.)

Pines, J. 1993. Cyclins and cyclin-dependent kinases: Take your partners. Trends Biochem. Sci. 18: 195-197.

Porro, D. and F. Srienc. 1995. Tracking of individual cell cohorts in asynchronous Saccharomyces cerevisiae populations. Biotechnol. Progress (in press).

Powers, S., T. Kataoka, O. Fasano, M. Goldfarb, J. Strathern, J. Broach, and M. Wigler. 1984. Genes in S. cerevisiae encoding proteins with domains homologous to the mammalian ras proteins. Cell 36: 607-612.

Ramer, S.W. and R.W. Davis. 1993. A dominant truncation allele identifies a gene, STE20, that encodes a putative protein kinase necessary for mating in Saccharomyces cerevisiae. Proc. Natl. Acad. Sci. 90: 452-456.

Richardson, H.E., C. Wittenberg, F. Cross, and S.I. Reed. 1989. An essential G1 function for cyclin-like proteins in yeast. Cell 59: 1127-1133.

Sanders, S.L. and C.M. Field. 1994. Septins in common? Curr. Biol. 4: 907-910.

Schuler, G.D., S.F. Altschul, and D.J. Lipman. 1991. A workbench for multiple alignment construction analysis. Proteins Struct. Funct. Genet. 9: 180-190.

Schwob, E. and K. Nasmyth. 1993. CLB5 and CLB6, a new pair of $B$ cyclins involved in $S$ phase and mitotic spindle formation in S. cerevisiae. Genes \& Dev. 7: 1160-1175.

Shinjo, K., J.G. Koland, M.J. Hart, V. Narashiman, D.I. Johnson, T. Evans, and R.A. Cerione. 1990. Molecular cloning of the gene for the human placental GTP-binding protein $\mathrm{Gp}(\mathrm{G} 25 \mathrm{~K})$ : Identification of this GTP-binding protein as the human homolog of the yeast cell-division cycle protein CDC42. Proc. Natl. Acad. Sci. 87: 9853-9857.

Sloat, B.F., A. Adams, and J.R. Pringle. 1981. Roles of the $C D C 24$ gene product in cellular morphogenesis during the Saccharomyces cerevisiae cell cycle. J. Cell Biol. 89: 395-405.

Stevenson, B.J., N. Rhodes, B. Errede, and G.F. Sprague Jr. 1992. Constitutive mutants of the protein kinase STE1l activate the yeast pheromone response pathway in the absence of the G protein. Genes \& Dev. 6: 1293-1304.

Tyers, M., G. Tokiwa, and B. Futcher. 1993. Comparison of the $S$. cerevisiae $\mathrm{Gl}$ cyclins: $\mathrm{Cln} 3$ may be an upstream activator of $C \ln 1, C \ln 2$ and other cyclins. EMBO J. 12: 1955-1968.

Zheng, Y., R. Cerione, and A. Bender. 1994. Control of the yeast bud-site assembly GTPase Cdc42. Catalysis of guanine nucleotide exchange by Cdc24 and stimulation of GTPase activity by Bem3. J. Biol. Chem. 269: 2369-2372.

Ziman, M., J.M. O'Brien, L.A. Ouellette, W.R. Church, and D.I. Johnson. 1991. Mutational analysis of CDC42Sc, a Saccharomyces cerevisiae gene that encodes a putative GTP-binding protein involved in the control of cell polarity. Mol. Cell. Biol. 11: 3537-3544.

Ziman, M., D. Preuss, J. Mulholland, J.M. O'Brien, D. Botstein, and D.I. Johnson. 1993. Subcellular localization of Cdc42p, a Saccharomyces cerevisiae GTP-binding protein involved in the control of cell polarity. Mol. Biol. Cell. 4: 1307-1316. 


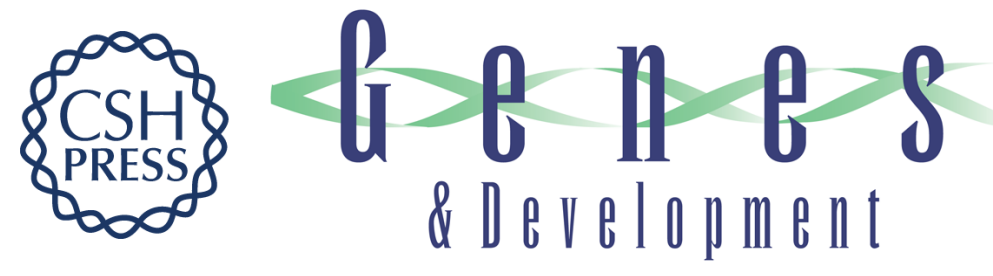

\section{Ste20-like protein kinases are required for normal localization of cell growth and for cytokinesis in budding yeast.}

F Cvrcková, C De Virgilio, E Manser, et al.

Genes Dev. 1995, 9:

Access the most recent version at doi:10.1101/gad.9.15.1817

References This article cites 55 articles, 21 of which can be accessed free at:

http://genesdev.cshlp.org/content/9/15/1817.full.html\#ref-list-1

License

Email Alerting

Service

Receive free email alerts when new articles cite this article - sign up in the box at the top right corner of the article or click here.

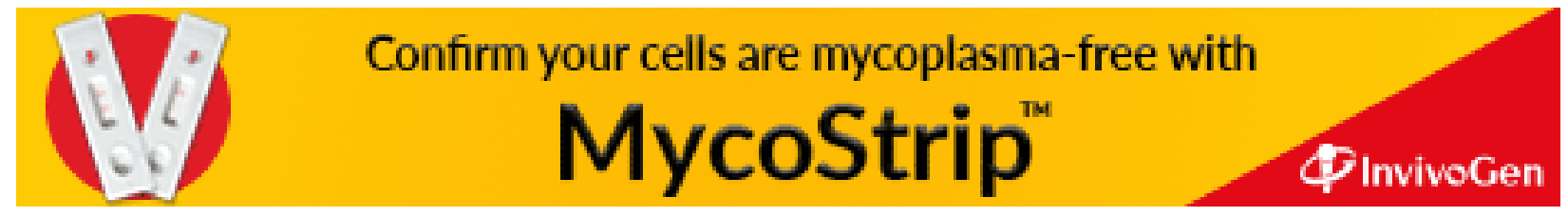

